\title{
The Relationship Between Eating Disorder Not Otherwise Specified (EDNOS) and Officially Recognized Eating Disorders: Meta-Analysis and Implications for DSM
}

\author{
Jennifer J. Thomas \\ Harvard Medical School and Yale University
}

\author{
Lenny R. Vartanian \\ Syracuse University
}

\author{
Kelly D. Brownell \\ Yale University
}

\begin{abstract}
Eating disorder not otherwise specified (EDNOS) is the most prevalent eating disorder (ED) diagnosis. In this meta-analysis, the authors aimed to inform Diagnostic and Statistical Manual of Mental Disorders revisions by comparing the psychopathology of EDNOS with that of the officially recognized EDs: anorexia nervosa (AN), bulimia nervosa (BN), and binge eating disorder (BED). A comprehensive literature search identified 125 eligible studies (published and unpublished) appearing in the literature from 1987 to 2007. Random effects analyses indicated that whereas EDNOS did not differ significantly from AN and BED on eating pathology or general psychopathology, BN exhibited greater eating and general psychopathology than EDNOS. Moderator analyses indicated that EDNOS groups who met all diagnostic criteria for AN except for amenorrhea did not differ significantly from full syndrome cases. Similarly, EDNOS groups who met all criteria for BN or BED except for binge frequency did not differ significantly from full syndrome cases. Results suggest that EDNOS represents a set of disorders associated with substantial psychological and physiological morbidity. Although certain EDNOS subtypes could be incorporated into existing Diagnostic and Statistical Manual of Mental Disorders (4th ed.; American Psychiatric Association, 1994) categories, others-such as purging disorder and non-fatphobic AN-may be best conceptualized as distinct syndromes.
\end{abstract}

Keywords: eating disorder not otherwise specified (EDNOS), eating disorder classification, DSM, meta-analysis

The systematic classification of mental disorders is an essential enterprise for both clinical research and treatment formulation because clearly defined symptom sets are the sine qua non of valid and reliable assessment. However, clinical cases do not necessarily fall neatly into predefined categories. For nearly every class of mental illness, the psychiatric community recognizes the possibility of clinically significant psychopathology that does not meet criteria for an established or emerging disorder. Since the third revision of the Diagnostic and Statistical Manual of Mental Dis-

Jennifer J. Thomas, Klarman Eating Disorders Center, McLean Hospital, Harvard Medical School, and Department of Psychology, Yale University; Lenny R. Vartanian, Department of Psychology, Syracuse University; Kelly D. Brownell, Department of Psychology, Yale University.

We thank the National Institutes of Mental Health for their financial support of this research project through the auspices of Ruth L. Kirschstein National Research Service Award F31MH078394. We also acknowledge the meticulous work of our study coders, Andres De Los Reyes, Kate A. McLaughlin, and Jessica M. Cronce. Lastly, we thank the investigators who contributed their in-press and unpublished studies for inclusion in our meta-analysis.

Correspondence concerning this article should be addressed to Jennifer J. Thomas, Eating Disorders Clinical and Research Program, Massachusetts General Hospital, WAC 816D, 15 Parkman Street, Boston, MA 02114. E-mail: jjthomas@partners.org orders (3rd ed., rev.; DSM-III-R; American Psychiatric Association [APA], 1987), these unclassifiable syndromes have been labeled "not otherwise specified" (NOS) and have been considered "atypical" remnants of our nosologic system. Residual categories have been accepted as a necessary compromise for the expedience of retaining clear thresholds for the diagnosis of established disorders and preserving the homogeneity of their clinical presentations, but this convenience comes at a cost. Recent data indicate that the majority of individuals with personality disorders (Johnson et al., 2005; Westen \& Arkowitz-Westen, 1998), dissociative disorders (Sar, Akyuz, \& Dogan, 2007), somatoform disorders (Kuwabara et al., 2007), and eating disorders (Fairburn \& Bohn, 2005) are diagnosed with the NOS subtype of these conditions. Because the heterogeneous NOS diagnosis undermines the utility of classifying mental disorders into homogeneous subtypes, its high prevalence can thwart areas as diverse as clinical communication, treatment planning, epidemiological inquiry, primary prevention, and basic research. The present study is a meta-analysis that examines the relationship between eating disorder NOS (EDNOS) and the officially recognized eating disorders.

EDNOS has received a great deal of research attention and therefore provides an illustrative example of the challenges inherent in assigning the majority of cases to the atypical category. Of the three eating disorders formally recognized in the Diagnostic and Statistical Manual of Mental Disorders (4th ed.; DSM-IV; 
APA, 1994; i.e., anorexia nervosa [AN], bulimia nervosa [BN], and EDNOS), EDNOS is by far the most prevalent. Recent research indicates that EDNOS comprises from $40 \%$ (Button, Benson, Nollett, \& Palmer, 2005; Ricca et al., 2001; Rockert, Kaplan, $\&$ Olmsted, 2007) to $60 \%$ (Fairburn et al., 2007; Martin, Williamson, \& Thaw, 2000; Nollet \& Button, 2005; Turner \& BryantWaugh, 2004; Williamson et al., 2002) of treatment-seekers at eating disorder specialty clinics. EDNOS may be even more widespread in nonspecialty settings: $90 \%$ of eating disorder patients in a community-based outpatient psychiatry practice (Zimmerman, Francione-Witt, Chelminski, Young, \& Tortolani, 2008) and 75\% of young women with eating disorders in a community prevalence study (Machado, Machado, Gonclaves, \& Hoek, 2007) received EDNOS diagnoses. EDNOS is especially common among populations that have received less research attention, such as men (Striegel-Moore, Garvin, Dohm, \& Rosenheck, 1999), ethnic minority groups (Alegria et al., 2007), aesthetically oriented athletes (Ringham et al., 2006), young children (Nicholls, Chater, \& Lask, 2000), and the elderly (Mangweth-Matzek et al., 2006).

The EDNOS category is so diverse that the label confers little information about a patient's likely symptoms, course, or outcome, thus undermining its utility as a diagnosis. Only one subtype of EDNOS, binge eating disorder (BED), features its own set of diagnostic criteria in $D S M-I V$. The remainder of EDNOS cases encompass individuals who exhibit partial syndromes ${ }^{1}$ of $\mathrm{AN}$ or $\mathrm{BN}$, show mixed features of both disorders, or have extremely atypical eating behaviors (e.g., chewing and spitting out large amounts of food without swallowing; APA, 2000). Because no $D S M$-defined boundary clearly differentiates EDNOS from patterns of unusual but nonpathological eating behavior, the conceptual definition of an "eating disorder" is ambiguous, and eating disorder caseness can only be identified in practice through idiosyncratic clinical judgments. Longitudinal studies highlight presentational heterogeneity, suggesting that whereas some cases of EDNOS are prone to spontaneous remission, others follow a chronic course. Although data on diagnostic cross-over in this population are limited, available findings suggest that approximately $40 \%$ of individuals with EDNOS go on to develop AN or BN within 1 year (Milos, Spindler, Schnyder, \& Fairburn, 2005) to 2 years (Herzog, Hopkins, \& Burns, 1993) of initial presentation. Longer term follow-up studies of individuals with EDNOS have identified remission rates of $50 \%$ after 3 years (Milos et al., 2005) and $80 \%$ after 5 years (Ben-Tovim et al., 2001; Grilo et al., 2007), with the remainder of patients retaining eating disorder diagnoses.

The high prevalence of EDNOS relative to officially recognized eating disorders renders the selection of empirically supported treatments difficult for the majority of eating disorder patients. Although cognitive-behavioral therapy and fluoxetine have demonstrated clear efficacy for the treatment of BN (Shapiro et al., 2007), and family-based therapy shows promise for the treatment of adolescent AN (Le Grange \& Lock, 2005), to date no evidencebased therapy has been developed specifically for EDNOS (with the notable exception of BED; Grilo, Masheb, \& Wilson, 2006; Peterson et al., 2001; Wilfley et al., 2002). EDNOS treatments are difficult to operationalize because of the heterogeneity of cases. In the absence of empirical guidance, clinicians are encouraged to cobble together techniques developed for the treatment of the other eating disorders (e.g., National Institute for Clinical Excellence, 2004). However, the efficacy of these borrowed approaches re- mains unknown. Early randomized controlled trials included only those participants who met strict diagnostic criteria for AN (e.g., Eisler et al., 1997) and BN (e.g., Fairburn et al., 1991), which could restrict their generalizeability to a subset of patients seen in actual clinical practice. In response to the low base rate of officially recognized disorders as well as an increasing number of studies that have questioned the validity of particular DSM-IV diagnostic requirements (Cachelin \& Maher, 1998; Le Grange et al., 2006), many treatment trials have begun combining therapy outcome data from EDNOS with that of AN and BN. Most notably, several AN trials have included participants who do not meet the amenorrhea criterion (McIntosh et al., 2005; Walsh et al., 2006), and several BN trials have included participants who report binge eating less than twice per week (Bara-Carril et al., 2004; Schmidt et al., 2006). The application of AN and BN treatments to EDNOS patients, and, conversely, the inclusion of EDNOS patients in AN and BN treatment trials, is predicated on the debatable hypothesis that the psychopathology of EDNOS is commensurate with that of the officially recognized eating disorders.

The current $D S M-I V$ criteria can also impede epidemiological inquiries into the prevalence of eating disorders. Traditional diagnostic instruments, such as the Structured Clinical Interview for DSM-IV (First, Spitzer, Gibbon, \& Williams, 1997), are likely to overlook EDNOS cases because they instruct assessors to skip out of the eating disorder module as soon as respondents fail to endorse one of the hallmark diagnostic criteria for AN or BN. Therefore, with a few recent exceptions (e.g., Hudson, Hiripi, Pope, \& Kessler, 2007; Wade, Bergin, Tiggemann, Bulik, \& Fairburn, 2006), the majority of epidemiological studies assessing eating disorder prevalence do not report population rates of EDNOS. Moreover, because EDNOS is defined in DSM-IV solely as a disorder that does not meet criteria for $\mathrm{AN}$ or $\mathrm{BN}$ and thus features no clear inclusion criteria, individual investigators must create operational definitions of EDNOS for use in epidemiological assessment. Even those investigations that do query for EDNOS typically limit their investigations to a circumscribed set of presentations, such as BED (Hudson et al., 2007), partial syndrome AN, or purging disorder (Wade et al., 2006), which may result in the underestimation of overall rates of eating disorder psychopathology in community samples.

\section{Potential DSM-V Solutions to the NOS Problem}

\section{The Evolution of Eating Disorder Diagnoses}

The identification of volitional self-starvation as the core phenomenology of AN (Gull, 1874; Laségue, 1873), and the bingepurge cycle as the hallmark of BN (Russell, 1979), emanated from idiographic assessment of clinical case series, which formed the first generation of eating disorder classification research. Although

\footnotetext{
${ }^{1}$ We use the term partial syndrome throughout this article to describe individuals who meet some but not all of the diagnostic criteria for one of the officially recognized eating disorders. Our use of the term partial syndrome is not meant to imply that individuals meeting some but not all diagnostic criteria for AN, BN, or BED exhibit eating pathology that is only partially as severe as individuals meeting full criteria. Indeed, the relative severity of EDNOS versus officially recognized eating disorders is exactly what our meta-analysis was designed to evaluate empirically.
} 
other clinical presentations were described in the early literatureincluding BED (Stunkard, 1959) and night eating syndrome (Stunkard, Grace, \& Wolff, 1955) — only AN and BN were formally recognized in the psychiatric nomenclature through the publication of the Diagnostic and Statistical Manual of Mental Disorders (3rd ed.; DSM-III; APA, 1980). To encompass alternative presentations, DSM-III also debuted a category for atypical eating disorders, or disorders of clinical significance that did not meet full criteria for $\mathrm{AN}$ or $\mathrm{BN}$. At the time, atypical eating disorders were thought to be rare (Ash \& Piazza, 1995) and received little empirical attention. As successive versions of the DSM (APA, 1987, 1994) prioritized the diagnostic reliability of $\mathrm{AN}$ and $\mathrm{BN}$ by promulgating objective thresholds for diagnosis (i.e. revising the suggested AN weight cutoff from $75 \%$ of original body weight to $85 \%$ of that expected; adding requirements that individuals with $\mathrm{BN}$ binge twice weekly and endorse compensatory behaviors), it became clear that a growing number of patients did not meet these new criteria. Thus atypical presentationsrenamed EDNOS in DSM-III-R to represent "disorders of eating that do not meet the criteria for a specific eating disorder" (APA, 1987, p. 71) and later exemplified with a nonexhaustive list of six possible presentations (APA, 1994; see Table 1)-became the topic of increased study. Longitudinal investigations suggest that the prevalence of EDNOS relative to $\mathrm{AN}$ and $\mathrm{BN}$ has increased over time (Ash \& Piazza, 1995), reflecting the growing heterogeneity of clinical cases. A wealth of data now suggest that, ironically, atypical eating disorders represent the most prevalent eating disorder diagnosis in both clinical (Fairburn et al., 2007; Zimmerman et al., 2008) and community (Machado et al., 2007) samples. Moreover, despite the perceived "subclinical" status of these atypical eating disorders, they may exhibit psychopathology commensurate to that of AN and BN (Fairburn et al., 2007). The strikingly high prevalence and severity of EDNOS relative to the officially recognized eating disorders introduces a nosologic paradox into our diagnostic system and calls into question how much is really known about the phenomenology of disordered eating.

\section{Four Different Proposals for DSM-V}

In response to the shortcomings of the current diagnostic system, investigators have embarked on a third generation of classification research assessing the validity of specific diagnostic criteria and, in turn, suggesting potential classificatory changes that could be adopted in $D S M-V$. Proposals parallel suggestions for nosologic improvement across several classes of mental disorders and, to some extent, reflect deep-rooted taxonomic debates between "lumpers" and "splitters." The first and most conservative solution would be to simply relax one or more criteria for the main eating disorders so as to subsume the majority of EDNOS patients into the officially recognized categories (Andersen, Bowers, \& Watson, 2001; Mitchell et al., 2007). For example, the diagnostic criteria for AN could be made more lenient by omitting the amenorrhea criterion (Cachelin \& Maher, 1998) or increasing the weight cutoff (Watson \& Andersen, 2003). Similarly, the criteria for $\mathrm{BN}$ could be relaxed so as to include individuals who binge less than twice per week (Le Grange et al., 2006; Rockert et al., 2007) or whose binge episodes are not objectively large (Keel, Mayer, \& Harnden-Fischer, 2001). Relaxing the current criteria would represent a constructive solution to the EDNOS problem if specific criteria could be identified that do not distinguish well between full and partial syndrome cases. To date, attempts to identify such criteria have not yet converged on obvious candidates. For example, although some investigations have found few differences between individuals with $\mathrm{BN}$ versus those who meet all criteria for

Table 1

DSM-IV-TR Definition and Example Presentations of EDNOS

\begin{tabular}{|c|c|}
\hline Definition of EDNOS & Example presentations of EDNOS \\
\hline $\begin{array}{l}\text { The EDNOS category is for disorders of eating that do } \\
\text { not meet criteria for any specific eating disorder. }\end{array}$ & $\begin{array}{l}\text { 1. For females, all of the criteria for AN are met } \\
\text { except that the individual has regular menses. } \\
\text { 2. All of the criteria for AN are met except that, } \\
\text { despite significant weight loss, the } \\
\text { individual's current weight is in the normal } \\
\text { range. } \\
\text { 3. All of the criteria for BN are met except that } \\
\text { the binge eating and inappropriate } \\
\text { compensatory mechanisms occur at a } \\
\text { frequency of less than twice a week or for a } \\
\text { duration of less than } 3 \text { months. } \\
\text { 4. The regular use of inappropriate } \\
\text { compensatory behavior by an individual of } \\
\text { normal body weight after eating small } \\
\text { amounts of food (e.g., self-induced vomiting } \\
\text { after the consumption of two cookies). } \\
\text { 5. Repeatedly chewing and spitting out, but not } \\
\text { swallowing, large amounts of food. } \\
\text { 6. BED: recurrent episodes of binge eating in } \\
\text { the absence of the regular use of inappropriate } \\
\text { compensatory behaviors characteristic of BN. }\end{array}$ \\
\hline
\end{tabular}

Note. Reprinted with permission from the Diagnostic and Statistical Manual of Mental Disorders, Text Revision, Fourth Edition (Copyright 2000). American Psychiatric Association. EDNOS = eating disorder not otherwise specified; $\mathrm{AN}=$ anorexia nervosa; $\mathrm{BN}=$ bulimia nervosa; $\mathrm{BED}=$ binge eating disorder. 
BN except binge frequency (e.g., Le Grange et al., 2006; Le Grange, Loeb, Van Orman, \& Jellar, 2004), others have identified significantly greater psychopathology among individuals with full syndrome BN (Crow, Agras, Halmi, Mitchell, \& Kraemer, 2002).

Alternatively, Fairburn and Bohn (2005) have proposed a more revolutionary transdiagnostic solution that would aggregate individuals currently diagnosed with $\mathrm{AN}, \mathrm{BN}$, and EDNOS into the single superordinate category of "eating disorder." Under the transdiagnostic model, eating disorder caseness would be established by evaluating the overall level of clinical impairment engendered by aberrant eating attitudes and behaviors, rather than prioritizing the frequency or severity of individual symptoms (Bohn et al., 2008; Fairburn \& Bohn, 2005). This strategy would eliminate specific eating disorder diagnoses altogether to create a unitary diagnosis that underscores key similarities across the eating disorders, including dietary restraint, binge eating, compensatory purging, body checking, and weight preoccupation (Fairburn $\&$ Bohn, 2005). Combining the three eating disorders under one umbrella diagnosis in $D S M-V$ would better reflect the frequent diagnostic migration observed in longitudinal studies (Herzog et al., 1993; Milos et al., 2005), which may be indicative of a shared etiological mechanism (Milos et al., 2005). Data supporting the adoption of the transdiagnostic model are mixed. Although some studies have observed similar levels of psychopathology in EDNOS versus officially recognized disorders (Garfinkel et al., 1995; Moor, Vartanian, Touyz, \& Beumont, 2004), others support the notion that EDNOS is a milder variant of eating pathology than either AN or BN (Dancyger \& Garfinkel, 1995).

A third possible solution to the EDNOS problem would be to identify and extract distinct diagnostic categories from within the heterogeneous EDNOS group. BED (Spitzer et al., 1991) has already received provisional $D S M-I V$ status as a diagnostic category nominated for further research, and candidates for new $D S M-V$ eating disorder diagnoses include both purging disorder (recurrent purging in the absence of objectively large binge episodes; Keel, Haedt, \& Edler, 2005) and night eating syndrome (a pattern of frequent and distressing nocturnal overeating; Allison, Grilo, Masheb, \& Stunkard, 2005). However, the benefits of enhanced nosologic coverage must be balanced with the possible risks of overpathologizing normative behaviors and introducing unwanted redundancies with existing categories (Pincus, Frances, Davis, First, \& Widiger, 1992). Identifying new eating disorders would only be prudent if investigators can unearth homogeneous subtypes of EDNOS that both differ meaningfully from AN and $\mathrm{BN}$ and are associated with substantial psychosocial impairment.

At an even finer grained level of distinction, the $D S M-V$ could conceptualize eating disorder subtypes as occupying specific positions in a more general multidimensional space (Beumont, Garner, \& Touyz, 1994; Williamson, Gleaves, \& Stewart, 2005). A dimensional model of eating disorders dovetails with proposals to define personality disorders as maladaptive extremes of the Big Five personality traits (cf. Widiger, 1993). The frequent need for NOS diagnoses represents a limitation inherent to any categorybased nosological system, and thus a dimensional model of eating pathology would obviate the need for an atypical category. Beumont et al. (1994) have proposed a three-dimensional system in which all individuals are diagnosed with a dieting disorder but are then further differentiated by the severity of key symptoms, including body mass index, binge eating, and purging. Recent taxo- metric investigations provide some support for a model in which anorexic symptoms are continuous with normality (Williamson et al., 2002), but findings suggesting that bulimic symptoms represent a discrete latent taxon (Gleaves, Lowe, Snow, Green, \& Murphy-Eberenz, 2000; Williamson et al., 2002) challenge purely dimensional conceptualizations.

\section{To What Extent Does EDNOS Differ From Established $D S M-I V$ Eating Disorders?}

All of the new diagnostic proposals represent creative attempts to solve a diagnostic dilemma in which the majority of clinical cases are relegated to the atypical category. To choose among them, or design another alternative solution, the field must weigh the empirical merits of each. In the absence of more robust data on diagnoses, DSM-III-R and DSM-IV decision makers were forced to rely on an extremely modest empirical base when considering potential diagnostic revisions. Fortunately, more than 100 studies have compared various subtypes of EDNOS with the officially recognized eating disorders since the 1994 publication of DSM-IV. These comparisons provide a wealth of data on whether and where $D S M-V$ diagnostic boundaries should be drawn among $\mathrm{AN}, \mathrm{BN}$, and EDNOS subtypes. However, conflicting findings, low statistical power, and different definitions of EDNOS across studies have hindered the ability of this literature to foster consensus on suggested revisions. Meta-analysis overcomes these methodological and interpretive difficulties by pooling effect sizes across studies, which enhances statistical power to determine the magnitude and statistical significance of overall effects. Meta-analytic techniques also capitalize on heterogeneity in study design by identifying study level characteristics (moderator variables) that are systematically associated with larger versus smaller effects.

The purpose of the present study was to conduct the first meta-analytic comparison of EDNOS versus the officially recognized $D S M-I V$ eating disorders (AN, BN, and BED). Our study comprised three overarching objectives:

1. We aimed to provide a comprehensive, quantitative summary of the differences in eating pathology, general psychopathology, and physical health between EDNOS and each of the officially recognized eating disorders. Although small to negligible differences would support the potential application of a transdiagnostic approach in $D S M-V$, larger differences would confirm the construct validity of extant categories.

2. We evaluated potential moderators of effect size with special emphasis on identifying specific diagnostic criteria that do not distinguish well between full syndrome and partial syndrome AN, BN, and BED. Such criteria could be considered potential candidates for omission in $D S M-V$.

3. We identified theoretical and methodological limitations of the literature to highlight productive directions for future research.

In sum, we hoped to first clarify the relative status of each EDNOS subtype, and subsequently highlight potential subgroups that could be removed from this problematic diagnostic category in 
future schemes for eating disorder classification to enhance clinical communication, treatment planning, epidemiological inquiry, and basic research.

Despite its provisional DSM-IV status, we treated BED as an officially recognized eating disorder in the present meta-analysis. We anticipated that organizing the data in this way would be optimally informative because a great deal is already known about BED; a recent review of its nosological status revealed that it has been the topic of more than 1,000 scientific articles (StriegelMoore \& Franko, 2008). Importantly, several latent class analyses support the distinctiveness of BED from BN (Bulik, Sullivan, \& Kendler, 2000; Pinheiro, Bulik, Sullivan, \& Machado, 2008; Striegel-Moore et al., 2005), long-term outcome studies suggest that BED is a stable syndrome (Pope et al., 2006), and behavioral genetic investigations highlight a pattern of familial aggregation consistent with genetic effects (Javaras et al., 2008). Thus, although the $D S M-V$ Work Group has not yet determined whether BED will be promoted to official eating disorder status in $D S M-V$, the more pressing question to eating disorder diagnosticians is how $D S M-V$ should classify the heterogeneous remainder of EDNOS cases. Indeed, many classification studies already treat BED as a disorder distinct from $\mathrm{AN}, \mathrm{BN}$, and other EDNOS subtypes, including several that have compared BED with subthreshold BED to evaluate the validity of specific diagnostic criteria (e.g., Cachelin et al., 1999; Crow et al., 2002; Fitzgibbon, Sanchez-Johnsen, \& Martinovich, 2003). Treating BED as an officially recognized eating disorder in the present meta-analysis allowed us to evaluate the potential magnitude and significance of these effects.

\section{Proposed Moderators of Effect Size}

\section{Diagnostic Factors}

Individual diagnostic criteria for $A N, B N$, and BED. The moderator of primary interest to our investigation was the diagnostic composition of the EDNOS group featured in each study. Although some studies have compared relatively heterogeneous groups of EDNOS participants with their counterparts diagnosed with AN, BN, or BED (e.g., Clinton \& Norring, 1999; Moor et al., 2004), others have examined specific groups of individuals who meet some but not all criteria for AN (e.g., Cachelin \& Maher, 1998; Roberto, Steinglass, Mayer, Attia, \& Walsh, 2007), BN (e.g., Fitzgibbon et al., 2003; Le Grange et al., 2006), or BED (e.g., Friederich et al., 2007). Variation in the diagnostic features of EDNOS across studies provides an ideal source of data for evaluating the validity of competing proposals for $D S M-V$ revisions. Specifically, nonsignificant differences between individuals who meet all but one criterion for a particular full syndrome diagnosis (e.g., AN without amenorrhea or $\mathrm{BN}$ with less than twice-weekly binge eating) across multiple studies would provide empirical support for recommendations to omit (or relax) that criterion in $D S M-V$. In contrast, large differences between officially recognized disorders and individuals who fail to meet a particular diagnostic criterion would be consistent with the retention of that criterion, and would support the discriminant validity of extant $D S M-I V$ thresholds. Lastly, small to negligible differences between officially recognized eating disorders and individual subtypes of EDNOS across all three meta-analyses could be interpreted as consistent with recommendations to embrace a transdiagnostic conceptualization of eating disorders (Fairburn \& Bohn, 2005) in $D S M-V$, although admittedly our meta-analysis cannot provide evidence for or against collapsing across the officially recognized categories of $\mathrm{AN}, \mathrm{BN}$, or BED.

Structured interview. The use of structured clinical interviews to establish psychiatric diagnoses enhances interrater reliability and diagnostic accuracy (Garb, 1998). Because power to detect differences between EDNOS and officially recognized eating disorders should be enhanced with increasingly valid and reliable assessments, we predicted that studies using structured interviews to establish eating disorder diagnoses would exhibit larger effect sizes than those relying on unstructured interviews or self-report measures. Alternatively, the use of structured interviews could potentially lead to smaller differences between EDNOS and officially recognized disorders if assessors who relied on unstructured assessment protocols conferred the EDNOS diagnosis to all treatment-seekers reporting eating-related distress, rather than placing systematic exclusion criteria on the EDNOS diagnosis. The inclusion of relatively healthy individuals in the EDNOS group could dilute observed levels of eating pathology. To evaluate these competing hypotheses, we examined the use of structured interviews as a potential moderator variable.

\section{Demographic Factors}

Patient sample. Although the majority of studies evaluating differences between EDNOS and officially recognized eating disorders are based on patient samples, an increasing number of studies have recruited non-treatment-seekers from the community. Previous research has established that greater psychosocial impairment and general psychopathology is associated with increased treatment utilization among individuals with eating disorders (Keel et al., 2002). Greater overall levels of psychopathology in treatment-seekers could overshadow between-groups differences in diagnostic status by creating a ceiling effect. Therefore, we hypothesized that differences between EDNOS and officially recognized eating disorders would be smaller in samples consisting of psychiatric inpatients or outpatients than in nonpatient community samples.

Participant age. Disproportionately high rates of EDNOS among children have prompted criticism of the DSM-IV criteria for their presumed inability to capture clinically significant eating pathology in young people (Nicholls et al., 2000). Indeed, investigators have described new eating disorders, such as selective eating disorder (Bryant-Waugh, 2000) and food avoidance emotional disorder (Higgs, Goodyer, \& Birch, 1989), which may better encapsulate these unique presentations. In contrast, other theorists have proposed that adolescent EDNOS may signify a prodromal "disorder in evolution" (Le Grange et al., 2004, p. 481) that presages the ultimate development of full-blown AN or BN. Longitudinal investigations have provided some support for adolescent EDNOS as a risk factor for AN and BN (Chamay-Weber, Narring, \& Michaud, 2005). Thus, we predicted that differences between EDNOS and officially recognized disorders would vary by age. More pronounced differences in younger age groups would provide support for the recognition of unique childhood eating disorders, whereas smaller differences in younger age groups would bolster the conceptualization of EDNOS as a precursor to one of the established eating disorders. 
Method

\section{Literature Search}

To obtain an exhaustive list of EDNOS studies, we conducted a four-step literature search. First, we searched five electronic databases-PsycINFO, Medline, PubMed, Excerpta Medica Database (EMBASE), and Cumulative Index to Nursing and Allied Health Literature (CINAHL) - to identify studies containing the terms "eating disorder $\$ 2$ not otherwise specified" and "EDNOS." Because authors do not always use the term EDNOS to describe eating disorders not meeting full criteria for $\mathrm{AN}, \mathrm{BN}$, or BED, the four databases that feature the capability to search for adjacent words within the body of an article (PsycINFO, Medline, EMBASE, and CINHAL) were additionally queried with the terms "eating disorder," "anorex\$" (anorexia or anorexic), "bulimi\$" (bulimia or bulimic), and "binge eating disorder" adjacent within five words to the terms "atypical," "partial," "residual," "subclinical," "subthreshold," "subsyndromal," “continuum," "unspecified," "non-specified," "NOS," or “non-classified." Second, we scanned the reference sections of all eligible studies identified through the electronic database search for additional citations. Third, we hand-searched the January 1987 through February 2007 issues of the four journals identified by the SCOPUS database to publish the highest number of articles on eating disorders (International Journal of Eating Disorders, European Eating Disorders Review, Eating and Weight Disorders, and American Journal of Psychiatry) to locate eligible studies. Fourth, in appreciation of the potential misrepresentation of population effect sizes due to the greater likelihood that significant (vs. nonsignificant) findings will be accepted for publication (Rosenthal, 1979), we sought out unpublished works via (a) searching for the terms "eating disorder\$ not otherwise specified" and "EDNOS" in the ProQuest Dissertations and Theses electronic database, and (b) e-mailing requests for unpublished or in-press studies to the corresponding authors of each of the eligible studies.

\section{Inclusion Criteria}

To ensure a minimum standard of methodological quality and comparability among studies included in the meta-analysis, we required that studies meet each of the following eligibility criteria: ${ }^{3}$

1. AN and BN studies needed to be published between January 1987 and February 2007. We selected this range because the 1987 publication of the DSM-III-R marked the advent of EDNOS as a diagnostic category as well as several substantial revisions to the diagnostic criteria for $\mathrm{AN}$ and $\mathrm{BN}$. The diagnostic criteria for $\mathrm{AN}$ and $\mathrm{BN}$ remained consistent from $D S M-I I I-R$ (APA, 1987) to $D S M-I V$ (APA, 1994), with the exception of minor changes in phrasing. Thus studies utilizing DSM-III-R, $D S M-I V$, or International Statistical Classification of Diseases and Related Health Problems-10th Edition (ICD-10; World Health Organization, 1992-1994) criteria for assignment to diagnostic categories were included in the AN and BN meta-analyses, whereas studies utilizing earlier criterion sets-such as Feighner et al. (1972), ICD-9 (World Health Organization, 1977), Russell (1979), and DSM-III (APA, 1980)—were not. Because
Spitzer et al. first proposed BED as a diagnostic category in late 1991, studies included in the BED portion of the meta-analysis needed to be published in 1992 or later. Studies were eligible for the BED meta-analysis only if they utilized Spitzer et al.'s (1991, 1992, or 1993) or $D S M-I V$ diagnostic criteria (which are virtually identical to Spitzer et al.'s criteria). Studies that utilized a lenient interpretation of otherwise includable criterion sets (e.g., relaxing the weight criterion for $\mathrm{AN}$, or relaxing the binge frequency requirement for $\mathrm{BN}$ ) were excluded.

2. Eligible studies must have reported data on measures of eating pathology, general psychopathology, or physical health for EDNOS versus AN, BN, or BED. We selected eating pathology, general psychopathology, and physical health as dependent variables because of their relevance to clinical practice as demonstrated by their frequent use as dependent measures in treatment efficacy trials (e.g., Fairburn et al., 1991; Peterson et al., 2001; Walsh et al., 2006) and longitudinal outcome studies (e.g., Ben-Tovim et al., 2001; Schork, Eckert, \& Halmi, 1994). An additional benefit of using scores on these particular measures was the clear interpretability of effect size direction as indicative of superior functioning in one diagnostic group versus another. The dependent variables were defined broadly such that eating pathology encompassed continuous measures-for example, subscales of the Eating Disorder Examination Questionnaire (Fairburn \& Beglin, 2008) or Eating Disorder Inventory (Garner, Olmstead, \& Polivy, 1983) — as well as the presence or frequency of eating disorder symptoms (e.g., dieting, chewing and spitting out food, body checking). Symptoms named as diagnostic criteria for $\mathrm{AN}, \mathrm{BN}$, or BED (e.g., body weight, binge frequency) were not included as dependent variables in that particular meta-analysis because observed differences on these variables would stem tautologically from the diagnostic boundaries between the two groups. For example, we did not use amenorrhea as a dependent variable in studies comparing AN with EDNOS, but we did use amenorrhea as a dependent variable in studies comparing BN with EDNOS. Similarly, we did not use specific measures of "fat phobia" as a dependent variable for the AN versus EDNOS meta-analysis, although to preserve the integrity of the category of eating pathology, we did include global measures of eating pathology that

\footnotetext{
${ }^{2}$ The "\$" following the operand enables the search engine to identify terms that begin with the operand but feature multiple endings (i.e., noun, adjective, or plural forms).

${ }^{3}$ While piloting the coding manual, coders attempted to evaluate individual study quality. Specifically, they attempted to record (a) whether the EDNOS and full syndrome groups were matched on demographic characteristics such as age and sex, (b) whether authors had $80 \%$ power to detect a medium effect size, and (c) the reliability of diagnostic and dependent measure(s). Because the majority of studies did not report this information and it was thus not possible to include quality as weighting variable, we attempted to investigate the effects of a key measure of study quality integral to the diagnostic process (the use of a structured interview to assign participants to diagnostic categories) in our moderator analyses.
} 
contained some items addressing weight and shape concerns. General psychopathology comprised both continuous measures-for example, the Beck Depression Inventory (Beck, Ward, Mendelson, Mock, \& Erbaugh, 1961), Symptom Checklist-90 (Derogatis, Rickels, \& Rock, 1976), and State-Trait Anxiety Inventory (Spielberger, Gorsuch, Lushene, Vagg, \& Jacobs, 1983)—and comorbid psychiatric diagnoses (e.g., major depressive disorder, borderline personality disorder). Example physical health indices included gastrointestinal disorders, attenuated bone mineral density, and vitamin deficiencies.

3. Eating disorder diagnoses must have been established via clinical interviews or well-validated self-report questionnaires that specifically operationalized the diagnostic criteria for $\mathrm{AN}, \mathrm{BN}, \mathrm{BED}$, and EDNOS. ${ }^{4}$ Each of the eligible self-report measures had exhibited adequate concordance rates with structured interview diagnoses in previous studies, including the Eating Disorder Examination Questionnaire (Wolk, Loeb, \& Walsh, 2005), the Eating Disorder Diagnostic Scale (Stice, Fisher, \& Martinez, 2004), and the Questionnaire for Eating and Weight Patterns (De Zwaan et al, 1993).

4. Eating disorder diagnoses needed to reflect current (rather than past or lifetime) diagnostic status, and dependent measures must have assessed current (rather than past) symptoms. Recent research has demonstrated substantial diagnostic cross-over between EDNOS and officially recognized eating disorders over time (Herzog et al., 1993; Milos et al., 2005). Therefore, studies reporting comparisons between individuals who met lifetime (but not current) criteria for an eating disorder were excluded. When studies reported both past and current symptoms for groups that currently met criteria for $\mathrm{AN}, \mathrm{BN}, \mathrm{BED}$, or EDNOS, coders extracted effect size information on current symptoms only.

5. EDNOS and AN, BN, or BED groups must have been sampled from the same population, as differential recruitment strategies across groups raise the possibility that differences between the two groups could stem from sample ascertainment (e.g., clinic-based vs. universitybased) rather than diagnostic status.

6. Eligible studies needed to report sufficient information with which to calculate effect sizes, such as means and standard deviations, frequency counts, raw data, $p$ values, and/or test statistics.

7. Studies were required to report data on at least 5 participants in each diagnostic category to promote the stability of effect size estimates.

8. Only reports written in English were included.

At the end of the search process, we identified 125 eligible research reports, including 118 published studies and 7 unpublished studies. Of these, 84 reported AN versus EDNOS compar- isons, 99 reported $\mathrm{BN}$ versus EDNOS comparisons, and 30 reported BED versus EDNOS comparisons.

\section{Study Coding}

Two coders independently extracted moderator and effect size data from each study. Coders included Lenny R. Vartanian; a postdoctoral fellow who coded all of the studies; and three clinical psychology doctoral students who coded the AN, BN, and BED studies, respectively. Before coding, each coder was trained in the use of the coding manual and coded seven practice studies. To investigate potential moderator effects, coders recorded the following features of each study: the diagnostic features of EDNOS subgroup(s) (see Table 2), whether investigators utilized structured interviews to assign participants to diagnostic categories, whether participants consisted of patients or nonpatients, and participants' mean age. Coders reviewed studies in sets of 20 to avoid coder drift and fatigue, and they participated in biweekly consensus meetings with Jennifer J. Thomas subsequent to each study set to ensure reliability and adherence to the coding manual. Table 3 presents interrater reliability coefficients for coders' initial ratings of putative moderator variables (prior to consensus meetings), in terms of kappa for categorical moderator variables, and intraclass correlation coefficients for continuous moderator variables. Coefficients ranged from .71 to 1.00 , indicating an adequate level of agreement (Landis \& Koch, 1977). In cases in which coders disagreed on study ratings, discrepancies were resolved through coder discussion, additional review of the article in question, and, when necessary, revision of the coding manual to achieve consensus and avoid future discrepancies.

\section{Meta-Analytic Procedures}

Calculation of standardized mean difference (Cohen's d). All effect sizes were calculated as the standardized mean difference of the dependent variable for AN versus EDNOS, BN versus EDNOS, or BED versus EDNOS. When studies provided means and standard deviations on continuous measures, we subtracted the mean of the EDNOS group from the mean of the AN, BN, or BED group and divided by the pooled standard deviation. Therefore, positive $d$ effect sizes indicate that individuals with officially recognized disorders exhibited greater pathology on a particular construct than individuals with EDNOS, whereas negative $d$ effect sizes indicate that EDNOS pathology was greater. When studies provided symptom frequency counts, we calculated odds ratios and transformed them into standardized mean differences. We interpreted effect sizes according to Cohen's (1988) criteria with absolute values of $0.2,0.5$, and 0.8 representing the guidelines for small, medium, and large effects, respectively.

Eight of the 125 eligible studies did not provide sufficient information from which to calculate effect sizes directly. Specifically, five studies reported group means but not standard deviations on well-validated dependent measures (e.g., Eating Disorder Inventory, Symptom Checklist-90), and three additional studies

\footnotetext{
${ }^{4}$ Studies utilizing patient samples were not required to explicitly state that they had diagnosed patients using a clinical interview because treatment status was assumed to imply that some form of clinical assessment had taken place.
} 
Table 2

Description of EDNOS Subgroups Used in Diagnostic Criteria Moderator Analyses

\begin{tabular}{|c|c|c|}
\hline Study type & EDNOS subgroup & Description of clinical features \\
\hline \multirow[t]{5}{*}{ AN studies } & AN with menses & $\begin{array}{l}\text { Meets all diagnostic criteria for AN except does not have } \\
\text { amenorrhea }\end{array}$ \\
\hline & High weight AN & $\begin{array}{l}\text { Meets all diagnostic criteria for AN except weighs }>85 \% \text { of } \\
\text { expected body weight }\end{array}$ \\
\hline & Non-fat-phobic AN & $\begin{array}{l}\text { Meets all diagnostic criteria for AN except does not endorse } \\
\text { intense fear of gaining weight or becoming fat }\end{array}$ \\
\hline & Partial AN & $\begin{array}{l}\text { Presents with features of } \mathrm{AN} \text { but missing at least } 2 \text { of the } 4 \\
\text { diagnostic criteria }\end{array}$ \\
\hline & Heterogeneous or other EDNOS & $\begin{array}{l}\text { Presents with eating disorder features not encompassed by } \\
\text { partial AN; or features a variety of different clinical } \\
\text { presentations; or clinical features not defined by the } \\
\text { investigators }\end{array}$ \\
\hline \multirow[t]{4}{*}{ BN studies } & Low binge frequency $\mathrm{BN}$ & $\begin{array}{l}\text { Meets all diagnostic criteria for BN except binges less often } \\
\text { than twice per week for a duration of at least } 3 \text { months }\end{array}$ \\
\hline & Purging disorder & $\begin{array}{l}\text { Meets all diagnostic criteria for BN except binges are not } \\
\text { objectively large }\end{array}$ \\
\hline & Partial BN & $\begin{array}{l}\text { Presents with features of BN but missing at least } 2 \text { of the } 5 \\
\text { diagnostic criteria }\end{array}$ \\
\hline & Heterogeneous or other EDNOS & $\begin{array}{l}\text { Presents with eating disorder features not encompassed by } \\
\text { partial BN; or features a variety of different clinical } \\
\text { presentations; or clinical features not defined by the } \\
\text { investigators }\end{array}$ \\
\hline \multirow[t]{3}{*}{ BED studies } & Low binge frequency BED & $\begin{array}{l}\text { Meets all diagnostic criteria for BED except binges less } \\
\text { often than twice per week for a duration of at least } 6 \\
\text { months }\end{array}$ \\
\hline & Partial BED & $\begin{array}{l}\text { Presents with some features of BED but missing at least } 2 \text { of } \\
\text { the } 5 \text { diagnostic criteria }\end{array}$ \\
\hline & Heterogeneous or other EDNOS & $\begin{array}{l}\text { Presents with eating disorder features not encompassed by } \\
\text { partial BED; or features a variety of different clinical } \\
\text { presentations; or clinical features not defined by the } \\
\text { investigators }\end{array}$ \\
\hline
\end{tabular}

Note. $\quad$ EDNOS $=$ eating disorder not otherwise specified; $\mathrm{AN}=$ anorexia nervosa; $\mathrm{BN}=$ bulimia nervosa; $\mathrm{BED}=$ binge eating disorder.

provided graphical rather than numerical representations of group differences. Omitting these studies from the meta-analysis would have (a) defeated our intended purpose of synthesizing all available comparisons between EDNOS and officially recognized eating disorders, and (b) potentially introduced bias into our analyses to the extent that studies with missing data differed on important design features from studies with nonmissing data. Therefore, we estimated effect sizes on the basis of past precedence. First, as recommended by Furukawa, Barbui, Cipriani, Brambilla, and

Table 3

Interrater Reliability for Proposed Moderators

\begin{tabular}{|c|c|c|c|c|c|c|}
\hline \multirow[b]{2}{*}{ Variable } & \multicolumn{2}{|c|}{ AN studies } & \multicolumn{2}{|c|}{ BN studies } & \multicolumn{2}{|c|}{$\begin{array}{l}\text { BED } \\
\text { studies }\end{array}$} \\
\hline & $k$ & ICC & $k$ & ICC & $k$ & ICC \\
\hline \multicolumn{7}{|l|}{ Categorical variables } \\
\hline EDNOS subgroup & .93 & & .71 & & .86 & \\
\hline Structured interview & .87 & & .88 & & .92 & \\
\hline Patient status & .94 & & .96 & & .92 & \\
\hline \multicolumn{7}{|l|}{ Continuous variables } \\
\hline Participant age & & .99 & & .91 & & 1.00 \\
\hline
\end{tabular}

Note. $\mathrm{AN}=$ anorexia nervosa; $\mathrm{BN}=$ bulimia nervosa $\mathrm{BED}=$ binge eating disorder; $\mathrm{ICC}=$ intraclass correlation coefficient; $\mathrm{EDNOS}=$ eating disorder not otherwise specified.
Watanabe (2006), we obtained standard deviations from previously established norms for eating disorder patients for use in effect size calculations in the case of missing variance estimates. Second, following Keel and Klump (2003), in three cases in which data were presented in graphic form only, coders measured the height of the graphs (intraclass correlation coefficient for interrater reliability $=1.00$ ) to determine group means. ${ }^{5}$

Adjusting for dependencies in the effect size distribution. To ensure the independence of effect sizes within each meta-analysis, we aggregated effect sizes at the study, sample, and construct levels. At the study level, multiple articles occasionally emanated from the same sample of participants. We considered studies to be duplicates only if investigators presented clearly identical data in more than one study, or explicitly cited another study that was also eligible for inclusion in the meta-analysis in which their data had already been reported. In the case of duplicate samples, we selected more recent studies over earlier studies, and peer-reviewed studies over book chapters or unpublished manuscripts. At the sample level, when investigators reported data separately for multiple subgroups of $\mathrm{AN}, \mathrm{BN}$, or BED participants (e.g., separate data for $\mathrm{BN}$-purging type and $\mathrm{BN}$-non-purging type), we collapsed

\footnotetext{
${ }^{5}$ Re-running our meta-analysis while excluding the eight studies that featured missing data did not substantively alter either the overall findings or the findings of individual moderator analyses.
} 
data from the two subgroups by taking the sample size-weighted mean and the pooled standard deviation to create an aggregate effect size for the overarching diagnostic category. Finally, at the construct level, the majority of studies utilized multiple measures of eating pathology, general psychopathology, and physical health. Rather than violating the independence assumption by allowing each sample to contribute multiple effect sizes or losing information by randomly selecting a single effect size, we averaged all measures of eating pathology emanating from the same study into a single effect size; we followed the same procedure for general psychopathology and physical health outcomes (cf. Ackerman, Beier, \& Boyle, 2005; Speilmans, Pasek, \& McFall, 2007). The only instance in which we allowed a study to contribute more than one effect size to the same meta-analysis was when investigators reported data for more than one diagnostic subtype of EDNOS. In that case, we included comparisons between each EDNOS subtype and its full syndrome counterpart to preserve information for the diagnostic criteria moderator analyses (which is analogous to previous meta-analyses comparing multiple treatment groups with the same control group to evaluate differential treatment efficacy; e.g., Weisz, McCarty, \& Valeri, 2006).

Random effects model. To determine the magnitude and significance of the overall effect size for each construct, we fit a random effects model. In contrast to a fixed effects approach, which assumes that individual effect sizes differ from the population mean through sampling error alone, a random effects approach assumes that variability among effect sizes is due to sampling error as well as unsystematic, random sources that vary across studies. Random effects models are more appropriate than fixed effects models for use with real-world data in which sample effect sizes are likely drawn from an underlying population in which effect size parameters themselves may vary (Field, 2003). Random effects models also feature the advantage of substantially reduced Type I error rates and enhanced ability to generalize findings beyond studies included in the meta-analytic sample because random effects approaches are more statistically conservative than fixed effects approaches (Field, 2003; Lipsey \& Wilson, 2001).

After calculating the overall effect size for each dependent variable, we evaluated the degree of heterogeneity in each effect size distribution by calculating the $Q$ statistic. We followed up significant $Q$ statistics with moderator analyses designed to evaluate whether variation could be explained in part by study-level characteristics recorded during the coding process. To evaluate the influence of categorical moderator variables, we utilized a mixed effects analogue to analysis of variance (ANOVA) that treated individual effect sizes as random effects, and moderator variables as fixed effects. Conceptualizing moderators as fixed (rather than random) in an overall mixed effects model was theoretically consistent with levels of each moderator representing mutually exclusive and collectively exhaustive definitions of naturally occurring population categories. For each ANOVA, we have provided a $Q$ statistic that evaluates whether the moderator accounts for a statistically significant proportion of the variation in the effect size distribution. Because each effect size in the present meta-analysis represents the standardized mean difference between EDNOS and an officially recognized eating disorder, a significant $Q$ statistic in the context of a moderator analysis indicates that these mean differences are significantly larger in some subgroups of studies and smaller in others. To investigate the influence of continuous moderator variables, we applied mixed effects regression on the basis of the method of moments estimation procedure. We conducted all statistical analyses using the Comprehensive MetaAnalysis Version 2.0 software program (Borenstein, Hedges, Higgins, \& Rothstein, 2005).

\section{Results}

\section{AN Versus EDNOS}

There were a total of 456 effect sizes from the 84 eligible studies that compared AN with EDNOS. Adjusting for dependencies in the effect size distribution by averaging nonindependent effects produced 73 effect sizes for eating pathology, 53 for general psychopathology, and 11 for physical health. Individual effect sizes from each study are displayed in Table 4, and results of moderator analyses are displayed in Table 5. Studies featured a median sample size of 88 participants, and aggregating across studies, a total of 11,557 participants were included in the AN meta-analyses.

Eating pathology. There was a trend for individuals with AN to score higher than individuals with EDNOS on measures of eating pathology $(d=0.09, S E=0.06,95 \%$ confidence interval $[\mathrm{CI}]=-0.01,0.20)$, but the difference was not statistically significant $(p=.09)$. The effect size distribution exhibited significant heterogeneity, $Q(72)=249.10, p<.001$, with effect sizes ranging from -1.50 to 2.72 (median $=0.11$ ), inviting the evaluation of moderator hypotheses. As predicted, the diagnostic features of EDNOS accounted for a significant proportion of the variance in the effect size distribution in a mixed effects ANOVA, $Q(4)=$ $10.50, p=.03$. Specifically, AN exhibited significantly higher levels of eating pathology than EDNOS groups meeting all criteria for AN except fat phobia $(d=0.74, p=.001) .{ }^{6}$ In contrast, AN did not differ significantly from EDNOS groups meeting all criteria for AN except amenorrhea $(d=0.20, p=.32)$, EDNOS groups meeting all criteria for AN except the weight criterion $(d=$ $-0.02, p=.93$ ), and EDNOS groups meeting at least two criteria for AN (partial AN; $d=-0.03, p=.72$ ). AN also did not differ from heterogeneously defined EDNOS groups or those that featured no information about their diagnostic characteristics $(d=$ $0.06, p=.37$ ). In contrast to our predictions, none of the remaining putative moderators accounted for a significant proportion of variability in the effect size distribution, including the use of structured interviews to assign participants to diagnostic categories, $Q(1)=$ $2.20, p=.14$; participant age, $Q(1)=2.53, p=.11$; and the use of a patient versus nonpatient sample, $Q(1)=0.00, p=.96$.

General psychopathology. Individuals with AN did not differ from individuals with EDNOS in terms of general psychopathology $(d=0.02, S E=0.05, p=.68,95 \% \mathrm{CI}=-0.07,0.11)$. Effect

\footnotetext{
${ }^{6}$ To evaluate whether potential overlap between the independent (fat phobia) and dependent (eating pathology) variables accounted for the large differences that we observed between full syndrome $\mathrm{AN}$ and non-fatphobic AN, we conducted a second trial of the AN diagnostic criteria moderator analysis in which we applied a more conservative definition of eating pathology among studies in the non-fat-phobic AN subgroup. Under this more conservative definition, we excluded dependent variables that had potential for overlap with fat phobia (such as the Drive for Thinness subscale of the Eating Disorder Inventory), and we obtained similar results.
} 
Table 4

Individual Effect Sizes for Studies Comparing Eating Disorder Not Otherwise Specified (EDNOS) With Anorexia Nervosa (AN)

\begin{tabular}{|c|c|c|c|c|c|c|c|c|c|c|c|}
\hline \multirow[b]{3}{*}{ Author (Year) } & \multirow[b]{3}{*}{$N$} & \multicolumn{4}{|c|}{ Moderator variables } & \multirow{2}{*}{\multicolumn{2}{|c|}{ Eating pathology }} & \multirow{2}{*}{\multicolumn{2}{|c|}{$\begin{array}{c}\text { General } \\
\text { psychopathology }\end{array}$}} & \multirow{2}{*}{\multicolumn{2}{|c|}{ Physical health }} \\
\hline & & \multirow{2}{*}{$\begin{array}{l}\text { EDNOS group } \\
\text { comparison }\end{array}$} & \multirow{2}{*}{$\begin{array}{l}\text { Patient } \\
\text { sample }\end{array}$} & \multirow{2}{*}{$\begin{array}{l}\text { Structured } \\
\text { interview }\end{array}$} & \multirow{2}{*}{$\begin{array}{c}\text { Mean } \\
\text { age }\end{array}$} & & & & & & \\
\hline & & & & & & $d(S E)$ & $p$ & $d(S E)$ & $p$ & $d(S E)$ & $p$ \\
\hline Alvarez-Rayon et al. (2004) & 174 & Heterogeneous & 1 & 0 & 18.98 & $0.39(0.17)$ & .02 & & & & \\
\hline \multirow[t]{2}{*}{ Andersen et al. (2001) } & 201 & AN with menses & 1 & 0 & & $0.42(0.19)$ & .02 & $0.12(0.18)$ & .51 & & \\
\hline & & High weight AN & 1 & 0 & & $-0.20(0.22)$ & .37 & $-0.43(0.22)$ & .06 & & \\
\hline Bean et al. (2005) & 96 & Heterogeneous & 1 & 0 & 26.88 & & & $0.12(0.26)$ & .64 & & \\
\hline Beumont et al. (1993) & 88 & Heterogeneous & 1 & 0 & 22.43 & $-0.05(0.22)$ & .82 & & & & \\
\hline Bjorck et al. (2003) & 457 & Heterogeneous & 1 & 1 & 24.90 & & & $0.27(0.10)$ & .01 & & \\
\hline Blinder et al. (2006) & 1,554 & Heterogeneous & 1 & 0 & 23.06 & & & $-0.02(0.17)$ & .89 & & \\
\hline Boyd et al. (2005) & 79 & Heterogeneous & 1 & 0 & 20.76 & $0.22(0.26)$ & .40 & $0.11(0.23)$ & .62 & $-0.30(0.25)$ & .23 \\
\hline Broberg et al. (2001) & 73 & Heterogeneous & 1 & 0 & 21.30 & $-0.10(0.25)$ & .69 & & & & \\
\hline Bryant-Waugh et al. (1996) & 16 & Heterogeneous & 1 & 0 & 09.50 & $1.24(0.58)$ & .03 & & & & \\
\hline Bunnell et al. (1992) & 68 & Heterogeneous & 1 & 0 & 15.31 & $-0.05(0.32)$ & .89 & & & & \\
\hline & & Partial AN & 1 & 0 & 15.31 & $0.05(0.27)$ & .87 & & & & \\
\hline Button et al. (2005) & 73 & Heterogeneous & 1 & 0 & 26.30 & $0.05(0.57)$ & .94 & & & & \\
\hline Cachelin et al. (1998) & 52 & AN with menses & 1 & 0 & 23.78 & $0.16(0.33)$ & .63 & $-0.14(0.33)$ & .68 & & \\
\hline Carlat et al. (1997) & 73 & Heterogeneous & 1 & 0 & 21.19 & $2.72(0.33)$ & .00 & $-0.37(0.44)$ & .40 & & \\
\hline Casasnovas et al. (2007) & 123 & Heterogeneous & 1 & 0 & 22.29 & $-0.03(0.18)$ & .87 & $0.16(0.18)$ & .38 & & \\
\hline Clinton and Glant (1992) & 30 & Heterogeneous & 1 & 0 & 25.17 & $-0.42(0.43)$ & .32 & $-0.16(0.58)$ & .78 & & \\
\hline Clinton and Norring (1999) & 201 & Heterogeneous & 1 & 0 & 25.20 & $-0.02(0.14)$ & .88 & & & & \\
\hline Clinton and Norring (2005) & 330 & Heterogeneous & 1 & 0 & 24.50 & $0.11(0.11)$ & .32 & $0.16(0.11)$ & .16 & & \\
\hline Corbridge and Bell (1996) & 61 & Heterogeneous & 1 & 0 & & $-0.36(0.48)$ & .45 & $0.21(0.69)$ & .76 & & \\
\hline Crow et al. (2002) & 194 & Heterogeneous & 0 & 1 & 30.60 & $0.04(0.19)$ & .82 & $0.57(0.20)$ & .00 & & \\
\hline & & Partial AN & 0 & 1 & 30.60 & $0.18(0.21)$ & .40 & $0.15(0.23)$ & .51 & & \\
\hline Cumella et al. (1999) & 170 & Heterogeneous & 1 & 0 & 16.03 & & & $0.12(0.18)$ & .50 & & \\
\hline Cumella et al. (2000) & 305 & Heterogeneous & 1 & 0 & 27.00 & & & $-0.01(0.12)$ & .94 & & \\
\hline Diaz et al. (2003) & 65 & Heterogeneous & 0 & 1 & 18.02 & $-0.36(0.25)$ & .16 & & & & \\
\hline Durham (1990) & 19 & Heterogeneous & 1 & 0 & 30.16 & $0.43(0.47)$ & .36 & $-0.35(0.52)$ & .50 & & \\
\hline Edwin and Andersen (1990) & 76 & Heterogeneous & 1 & 0 & 25.40 & $0.64(0.38)$ & .09 & & & & \\
\hline Ekeroth et al. (2003) & 179 & Heterogeneous & 1 & 1 & 15.43 & & & $0.01(0.15)$ & .93 & & \\
\hline Ekeroth et al. (2004) & 55 & Heterogeneous & 1 & 0 & 21.60 & & & $-0.13(0.27)$ & .64 & & \\
\hline Fairburn et al. (2005) & 85 & Heterogeneous & 0 & 1 & 19.56 & $-0.28(0.34)$ & .41 & & & & \\
\hline Fairburn et al. (2007) & 110 & Heterogeneous & 1 & 1 & 25.95 & $0.46(0.54)$ & .40 & $0.40(0.58)$ & .49 & & \\
\hline Favaro and Santonastaso & & & & & & & & & & & \\
\hline (1996) & 237 & Heterogeneous & 1 & 0 & & $-0.22(0.16)$ & .16 & & & & \\
\hline Favaro and Santonastaso & & & & & & & & & & & \\
\hline (1997) & 290 & Heterogeneous & 1 & 0 & 23.58 & & & $0.09(0.19)$ & .64 & & \\
\hline Fornari et al. (1994) & 123 & Heterogeneous & 1 & 0 & 19.60 & $-0.08(0.21)$ & .69 & $0.26(0.26)$ & .32 & & \\
\hline Fullerton et al. (1995) & 469 & Heterogeneous & 1 & 0 & 24.32 & & & $-0.34(0.17)$ & .04 & & \\
\hline Gerlinghoff et al. (1998) & 37 & Heterogeneous & 1 & 0 & 23.10 & $0.34(0.55)$ & .54 & $0.94(0.40)$ & .02 & & \\
\hline Ghadirian et al. (1999) & 55 & Heterogeneous & 1 & 0 & 28.59 & & & $0.01(0.29)$ & .96 & & \\
\hline Gleaves and Eberenz & & & & & & & & & & & \\
\hline (1995) & 26 & Heterogeneous & 1 & 0 & 26.50 & $0.03(0.43)$ & .95 & $0.00(0.43)$ & .99 & & \\
\hline Gleaves et al. (1998) & 191 & Heterogeneous & 1 & 0 & 24.56 & $0.45(0.15)$ & .00 & & & & \\
\hline Glorio et al. (2000) & 78 & Heterogeneous & 1 & 0 & 18.18 & & & & & $0.54(0.72)$ & .45 \\
\hline Godt (2002) & 95 & Heterogeneous & 1 & 1 & 23.39 & & & $-0.42(0.26)$ & .10 & & \\
\hline Godt (2008) & 312 & Heterogeneous & 1 & 1 & 23.80 & & & $-0.24(0.15)$ & .11 & & \\
\hline Goebel et al. (1999) & 85 & Heterogeneous & 1 & 1 & 26.64 & $0.16(0.46)$ & .73 & $-0.20(0.53)$ & .71 & $0.73(0.23)$ & .00 \\
\hline Griffiths et al. (1999) & 53 & Heterogeneous & 1 & 0 & 18.50 & $-0.41(0.28)$ & .15 & & & & \\
\hline Hasler et al. (2004) & 56 & Heterogeneous & 1 & 1 & 28.34 & & & $-0.48(0.30)$ & .11 & $-0.49(0.30)$ & .11 \\
\hline Joyce et al. (1990) & 16 & Heterogeneous & 1 & 0 & 29.24 & $1.74(0.90)$ & .05 & & & $-0.38(0.52)$ & .46 \\
\hline Kovacs et al. (2002) & 395 & Heterogeneous & 1 & 0 & & $0.27(0.16)$ & .09 & & & & \\
\hline & & Partial AN & 1 & 0 & & $-0.16(0.16)$ & .30 & & & & \\
\hline Kurth et al. (1995) & 52 & Heterogeneous & 0 & 1 & 17.70 & $-0.04(0.65)$ & .95 & & & & \\
\hline Le Grange et al. (2004) & 66 & Heterogeneous & 1 & 1 & 15.29 & $-0.91(0.26)$ & .00 & $-0.91(0.26)$ & .00 & & \\
\hline Lee et al. (1993) & 61 & Non-fat-phobic AN & 1 & 0 & 23.90 & $0.74(0.32)$ & .02 & & & & \\
\hline Lee et al. (1998) & 23 & Non-fat-phobic AN & 1 & 0 & 19.52 & $0.11(0.43)$ & .80 & & & & \\
\hline Lee et al. (2001) & 48 & Non-fat-phobic AN & 1 & 0 & 18.77 & $0.64(0.47)$ & .17 & $0.12(0.31)$ & .70 & $-0.19(0.31)$ & .54 \\
\hline Lee et al. (2002) & 109 & Non-fat-phobic AN & 1 & 0 & 20.63 & $0.72(0.20)$ & .00 & & & & \\
\hline Levine et al. (2007) & 23 & Heterogeneous & 1 & 1 & 21.80 & & & & & $-0.60(0.45)$ & .18 \\
\hline Maroñon et al. (2004) & 29 & Heterogeneous & 1 & 0 & 22.21 & & & $0.09(0.34)$ & .79 & & \\
\hline Martin et al. (2000) & 116 & Heterogeneous & 1 & 1 & 23.60 & $-0.35(0.26)$ & .18 & $-0.05(0.24)$ & .84 & & \\
\hline & & Partial AN & 1 & 1 & 23.60 & $-0.07(0.23)$ & .75 & $0.01(0.23)$ & .95 & & \\
\hline
\end{tabular}




\begin{tabular}{|c|c|c|c|c|c|c|c|c|c|c|c|}
\hline \multirow[b]{3}{*}{ Author (Year) } & \multirow[b]{3}{*}{$N$} & \multicolumn{4}{|c|}{ Moderator variables } & \multirow{2}{*}{\multicolumn{2}{|c|}{ Eating pathology }} & \multirow{2}{*}{\multicolumn{2}{|c|}{$\begin{array}{c}\text { General } \\
\text { psychopathology }\end{array}$}} & \multirow{2}{*}{\multicolumn{2}{|c|}{ Physical health }} \\
\hline & & \multirow{2}{*}{$\begin{array}{l}\text { EDNOS group } \\
\text { comparison }\end{array}$} & \multirow{2}{*}{$\begin{array}{l}\text { Patient } \\
\text { sample }\end{array}$} & \multirow{2}{*}{$\begin{array}{l}\text { Structured } \\
\text { interview }\end{array}$} & \multirow{2}{*}{$\begin{array}{c}\text { Mean } \\
\text { age }\end{array}$} & & & & & & \\
\hline & & & & & & $d(S E)$ & $p$ & $d(S E)$ & $p$ & $d(S E)$ & $p$ \\
\hline McDermott et al. (2006) & 95 & Heterogeneous & 1 & 1 & 14.50 & $-0.15(0.21)$ & .46 & $-0.64(0.21)$ & .00 & & \\
\hline Milos et al. (2003) & 111 & Heterogeneous & 0 & 1 & 25.74 & & & $0.38(0.24)$ & .11 & & \\
\hline Milos et al. (2004) & 130 & Heterogeneous & 0 & 1 & 28.42 & & & $0.40(0.25)$ & .11 & & \\
\hline Mizes et al. (2000) & 108 & Heterogeneous & 1 & 0 & 25.90 & $-0.02(0.19)$ & .94 & & & & \\
\hline Mizes et al. (2004) & 147 & Heterogeneous & 1 & 0 & 25.71 & $-0.19(0.20)$ & .34 & & & & \\
\hline Moor et al. (2004) & 46 & Heterogeneous & 1 & 0 & 21.30 & $-0.01(0.30)$ & .97 & $-0.11(0.30)$ & .71 & & \\
\hline \multicolumn{3}{|l|}{ Nevonen and Broberg } & & 0 & 20.90 & $-0.57(0.24)$ & .02 & & & & \\
\hline Nollett and Button (2005) & 115 & Heterogeneous & 1 & 1 & 27.00 & $0.18(0.21)$ & .38 & $0.34(0.21)$ & .10 & & \\
\hline Noma et al. (2006) & 50 & $\begin{array}{l}\text { Non-fat-phobic AN } \\
\text { Heterogeneous }\end{array}$ & $\begin{array}{l}1 \\
1\end{array}$ & $\begin{array}{l}0 \\
0\end{array}$ & $\begin{array}{l}26.62 \\
26.62\end{array}$ & $\begin{array}{l}2.37(0.72) \\
0.51(0.48)\end{array}$ & $\begin{array}{l}.00 \\
.28\end{array}$ & & & & \\
\hline $\begin{array}{l}\text { Panagiotopoulos et al. } \\
\text { (2000) }\end{array}$ & 88 & Heterogeneous & 1 & 0 & 15.01 & $-0.95(0.41)$ & .02 & & & $0.15(0.24)$ & .52 \\
\hline Probst et al. (1995) & 324 & Heterogeneous & 1 & 0 & 24.00 & $-0.42(0.16)$ & .01 & & & & \\
\hline \multirow[t]{2}{*}{ Ricca et al. (2001) } & 126 & Heterogeneous & 1 & 1 & 22.27 & $-0.45(0.20)$ & .03 & $-0.39(0.20)$ & .05 & & \\
\hline & & Partial AN & 1 & 1 & 22.27 & $0.28(0.25)$ & .26 & $0.02(0.25)$ & .94 & & \\
\hline Ro et al. (2005) & 34 & Heterogeneous & 1 & 1 & 29.70 & & & $0.00(0.36)$ & 1.00 & & \\
\hline Roberto et al. (2007) & 230 & AN with menses & 1 & 1 & 25.35 & $-0.25(0.17)$ & .14 & $-0.02(0.19)$ & .90 & & \\
\hline Salvemini et al. (2000) & 143 & Heterogeneous & 1 & 0 & 25.28 & $0.61(0.17)$ & .00 & $0.17(0.17)$ & .33 & & \\
\hline Schork et al. (1994) & 29 & Heterogeneous & 1 & 0 & & & & $0.70(0.44)$ & .12 & & \\
\hline Shafran et al. (2004) & 53 & Heterogeneous & 1 & 0 & 28.78 & $0.26(0.30)$ & .40 & $0.41(0.28)$ & .15 & & \\
\hline Solenberger (2001) & 161 & Heterogeneous & 1 & 0 & 20.05 & $0.44(0.19)$ & .02 & & & & \\
\hline Spindler and Milos (2007) & 125 & Heterogeneous & 0 & 1 & 27.34 & $0.83(0.20)$ & .00 & & & & \\
\hline Thurfjell et al. (2003) & 176 & Heterogeneous & 1 & 1 & 15.40 & $0.15(0.15)$ & .33 & & & & \\
\hline Tobin et al. (1997) & 66 & Heterogeneous & 1 & 0 & & $0.13(0.29)$ & .65 & & & & \\
\hline Troop et al. (2000) & 35 & Heterogeneous & 1 & 0 & 24.40 & $0.12(0.42)$ & .78 & & & & \\
\hline $\begin{array}{l}\text { Turner and Bryant-Waugh } \\
\text { (2004) }\end{array}$ & 145 & Heterogeneous & 1 & 1 & 26.91 & $0.10(0.31)$ & .75 & & & & \\
\hline \multicolumn{12}{|l|}{ Vandereycken and Pieters } \\
\hline (1992) & 237 & Heterogeneous & 1 & 0 & 22.62 & $-0.01(0.26)$ & .97 & $0.81(0.23)$ & .00 & & \\
\hline Vanderlinden et al. (1993) & 70 & Heterogeneous & 1 & 0 & 24.30 & & & $-0.42(0.32)$ & .19 & & \\
\hline \multicolumn{12}{|l|}{ Watson and Andersen } \\
\hline \multirow[t]{3}{*}{ (2003) } & 297 & AN with menses & 1 & 0 & 23.78 & $0.52(0.24)$ & .03 & $-0.17(0.23)$ & .47 & $0.09(0.22)$ & .66 \\
\hline & & High weight AN & 1 & 0 & 23.78 & $0.19(0.25)$ & .44 & $0.17(0.25)$ & .48 & $0.93(0.25)$ & .00 \\
\hline & & Partial AN & 1 & 0 & 23.78 & $-0.45(0.25)$ & .07 & $-0.47(0.25)$ & .07 & $0.67(0.27)$ & .01 \\
\hline Weltzin et al. (2007) & 74 & Heterogeneous & 1 & 0 & 23.51 & $0.32(0.28)$ & .26 & & & & \\
\hline Wilks (2006) & 10 & Heterogeneous & 1 & 0 & 23.50 & $0.21(0.63)$ & .74 & $0.38(0.64)$ & .56 & & \\
\hline \multirow[t]{2}{*}{ Williamson et al. (1992) } & 48 & Heterogeneous & 1 & 1 & & $-0.12(0.36)$ & .73 & & & & \\
\hline & & Partial AN & 1 & 1 & & $0.17(0.37)$ & .66 & & & & \\
\hline Williamson et al. (2002) & 102 & Heterogeneous & 1 & 1 & & $0.22(0.22)$ & .33 & & & & \\
\hline Wunderlich et al. (2004) & 43 & Heterogeneous & 1 & 0 & 21.00 & $-1.50(0.36)$ & .00 & & & & \\
\hline
\end{tabular}

Note. Blank cells in the table indicate that data for those variables were missing from the original research reports. Under "Patient sample," $1=$ psychiatric patients; $0=$ nonpatients only, or both patients and nonpatients. Under "Structured interview," 1 = eating disorder diagnoses established via structured interview; $0=$ diagnoses established via unstructured interview or self-report questionnaire.

sizes ranged from -0.91 to 0.94 (median $=0.02$ ), and exhibited significant heterogeneity, $Q(52)=101.90, p<.001$. With regard to putative moderators, patient samples $(d=-0.01, p=.76)$ exhibited significantly smaller effects than nonpatient samples $(d=0.39, p=.001), Q(1)=10.87, p=.001$, and effect sizes increased with increasing age, $Q(1)=5.94, p=.01$. However, neither the diagnostic features of EDNOS, $Q(4)=0.94, p=.92$, nor the use of clinical interviews to assign diagnoses, $Q(1)=0.78$, $p=.38$, were significant moderators of effect size.

Physical health. Lastly, AN did not differ significantly from EDNOS on measures of physical health $(d=0.14, S E=0.16, p=$ $.40,95 \% \mathrm{CI}=-0.18,0.45)$. The $Q$ statistic was indicative of significant heterogeneity in the effect size distribution, $Q(10)=$ $32.09, p<.001$, with effect sizes ranging from -0.60 to 0.93 (median $=0.09)$. Neither the use of a structured interview to assign diagnoses, $Q(1)=0.30, p=.59$, nor participant age, $Q(1)=0.00, p=.97$, accounted for a significant proportion of the variance in the effect size distribution. We did not investigate the potential effects of EDNOS diagnostic features and patient versus nonpatient sample because some levels of these moderators featured too few studies (i.e., zero or one).

\section{BN Versus EDNOS}

There were a total of 561 effect sizes from the 99 eligible studies that compared BN with EDNOS. Adjusting for dependencies in the effect size distribution by averaging nonindependent effects produced 82 effect sizes for eating pathology, 62 for general psycho- 
Table 5

Q Statistics and Effect Sizes for Eating Disorder Not Otherwise Specified (EDNOS) Versus Anorexia Nervosa (AN) Moderator Analyses

\begin{tabular}{|c|c|c|c|c|c|c|}
\hline Moderator & $Q$ & $p$ & Moderator levels & $d$ & $S E$ & $p$ \\
\hline \multicolumn{7}{|c|}{$\underline{\text { Eating pathology }}$} \\
\hline \multirow[t]{5}{*}{ EDNOS subgroup } & 10.50 & .03 & AN with menses & 0.20 & 0.20 & .32 \\
\hline & & & High weight AN & -0.02 & 0.19 & .93 \\
\hline & & & Non-fat-phobic AN & 0.74 & 0.23 & .001 \\
\hline & & & Partial AN & -0.03 & 0.09 & .72 \\
\hline & & & Heterogeneous or other EDNOS & 0.06 & 0.07 & .37 \\
\hline \multirow[t]{2}{*}{ Structured interview } & 2.20 & .14 & Structured interview & -0.02 & 0.08 & .84 \\
\hline & & & Unstructured interview or self-report & 0.15 & 0.07 & .04 \\
\hline \multirow[t]{2}{*}{ Patient status } & 0.00 & .96 & Patient sample & 0.09 & 0.06 & .11 \\
\hline & & & Nonpatient or mixed sample & 0.10 & 0.20 & .60 \\
\hline \multirow[t]{2}{*}{ Mean age } & 2.53 & .11 & & & & \\
\hline & & & General psychopathology & & & \\
\hline \multirow[t]{5}{*}{ EDNOS subgroup } & 0.94 & .92 & AN with menses & -0.02 & 0.11 & .88 \\
\hline & & & High weight AN & -0.14 & 0.30 & .65 \\
\hline & & & Non-fat-phobic AN & 0.12 & 0.31 & .70 \\
\hline & & & Partial AN & -0.06 & 0.13 & .66 \\
\hline & & & Heterogeneous or other EDNOS & 0.04 & 0.05 & .48 \\
\hline \multirow[t]{2}{*}{ Structured interview } & 0.78 & .38 & Structured interview & -0.04 & 0.09 & .68 \\
\hline & & & Unstructured interview or self-report & 0.05 & 0.05 & .30 \\
\hline \multirow[t]{2}{*}{ Patient status } & 10.87 & .001 & Patient sample & -0.01 & 0.05 & .76 \\
\hline & & & Nonpatient or mixed sample & 0.39 & 0.11 & .001 \\
\hline \multirow[t]{2}{*}{ Mean age } & 5.94 & .01 & & & & \\
\hline & & & $\underline{\text { Physical health }}$ & & & \\
\hline \multicolumn{7}{|l|}{ EDNOS subgroup } \\
\hline \multirow[t]{2}{*}{ Structured interview } & 0.30 & .59 & Structured interview & -0.08 & 0.47 & .87 \\
\hline & & & Unstructured interview or self-report & 0.20 & 0.17 & .25 \\
\hline \multicolumn{7}{|l|}{ Patient status } \\
\hline Mean age & 0.00 & .97 & & & & \\
\hline
\end{tabular}

Note. Under "Physical health," moderator analyses were not conducted for EDNOS subgroup and patient status because some levels of these moderators feature $\leq 1$ study.

pathology, and 14 for physical health. Studies featured a median sample size of 84 participants, and aggregating across studies, a total of 13,682 independent participants were included in the BN meta-analyses. Effect sizes for individual studies are displayed in Table 6. Table 7 summarizes the results of BN moderator analyses.

Eating pathology. $\mathrm{BN}$ scored significantly higher than EDNOS on measures of eating pathology $(d=0.39, S E=0.05, p<.001,95 \%$ $\mathrm{CI}=0.29,0.50)$. Effect sizes ranged from -1.11 to 2.50 , with a median of 0.41 . The $Q$ statistic confirmed significant heterogeneity in the effect size distribution, $Q(81)=329.81, p<.001$, inviting the evaluation of moderator hypotheses. Contrary to our prediction, the diagnostic features of EDNOS did not explain a significant proportion of the heterogeneity in the effect size distribution in a mixed effects ANOVA, $Q(3)=5.12, p=.16$. However, recognizing the potential importance of this putative moderator for $D S M-V$ revisions, we conducted focal analyses of a priori planned contrasts for each of the four diagnostic groups subsequent to the nonsignificant omnibus test (as described in Rosenthal, 1995; Rosenthal, Rosnow, \& Rubin, 2000). Planned contrasts suggested that effects were small to moderate when the EDNOS group met all criteria for BN except for objectively large binge episodes (i.e. purging disorder; $d=0.39, p<$ .001 ), when the EDNOS group missed two or more of the diagnostic criteria for BN (partial BN; $d=0.29, p=.01$ ), and when the EDNOS group was heterogeneously defined or no information was given about its clinical characteristics $(d=0.43, p<.001)$. In contrast, when the EDNOS group met all criteria for BN except the binge frequency criterion, differences from $\mathrm{BN}$ were small and nonsignificant $(d=0.10, p=.49)$. In addition, mixed effects regression indicated that mean participant age was inversely associated with effect size, $Q(1)=4.72, p=.03$, such that younger participants exhibited larger differences than older participants. Finally, use of a structured interview versus an unstructured interview or self-report instrument, $Q(1)=0.02, p=.89$, and recruitment of a patient versus nonpatient sample, $Q(1)=1.38, p=.24$, did not account for a significant proportion of the heterogeneity in the effect size distribution.

General psychopathology. BN groups scored significantly higher than EDNOS groups on general psychopathology, although the mean effect size was small $(d=0.19, S E=0.03, p<.001,95 \% \mathrm{CI}=$ $0.13,0.25)$. Effect sizes ranged from -1.36 to 0.79 , with a median of 0.17 . The $Q$ statistic did not reach significance, $Q(61)=72.82, p=$ .14 , so potential moderator effects were not investigated.

Physical health. In contrast to patterns for eating pathology and general psychopathology, EDNOS groups exhibited significantly poorer physical health than $\mathrm{BN}$ groups $(d=-0.18, S E=$ $0.08, p=.03,95 \% \mathrm{CI}=-0.34,-0.02$ ). Effects sizes ranged from -0.65 to 0.68 , with a median of -0.16 . Moderators were not 
evaluated because the $Q$ statistic did not reveal significant heterogeneity in the effect size distribution, $Q(13)=8.95, p=.78$.

\section{BED Versus EDNOS}

There were a total of 260 effect sizes from the 30 eligible studies that compared BED with EDNOS. Aggregating effect sizes to adjust for nonindependence produced 29 effect sizes for eating pathology and 24 for general psychopathology. We did not identify any studies comparing physical health variables between individuals with BED and EDNOS. The median sample size was 67 participants, and summing across all 30 studies, a total of 2,707 participants were included in the following analyses. Table 8 presents effect sizes for each of the individual BED studies, and Table 9 provides a summary of BED moderator findings.

Eating pathology. There was a trend for BED to score higher than EDNOS on measures of eating pathology $(d=0.17, S E=$ $0.09,95 \% \mathrm{CI}=-0.01,0.35)$, but the difference was not statistically significant $(p=.06)$. The effect size distribution exhibited significant heterogeneity, $Q(28)=100.39, p<.001$, with effect sizes ranging from -0.79 to 1.17 (median $=0.18$ ). As predicted, the diagnostic features of EDNOS accounted for a significant proportion of this heterogeneity, $Q(2)=9.85, p=.01$, according to mixed effects ANOVA. Specifically, BED groups scored significantly higher on measures of eating pathology than groups of partial BED participants who missed two or more of the diagnostic criteria for BED $(d=0.46, p<.001)$. However, BED did not differ significantly from EDNOS groups in which participants met all diagnostic criteria for BED except the binge frequency criterion $(d=0.28, p=.37)$, nor did it differ significantly from EDNOS groups that were heterogeneously defined or whose diagnostic characteristics were not specifically described $(d=-0.07, p=$ .58). In addition, studies that recruited patient samples yielded smaller effects $(d=-0.07, p=.67)$ than studies recruiting nonpatient or mixed samples $(d=0.35, p<.001), Q(1)=5.45$, $p=.02$. There was also a trend for studies utilizing structured interviews to find smaller differences $(d=-0.02, p=.91)$ than studies using unstructured interviews or self-report measures $(d=$ $0.33, p=.01), Q(1)=3.64, p=.06$. Finally, mean age of participants did not significantly predict effect size, $Q(1)=1.89$, $p=.17$.

General psychopathology. In line with findings for eating pathology, BED did not differ from EDNOS with regard to general psychopathology $(d=0.03, S E=0.07, p=.66,95 \% \mathrm{CI}=-0.10$, 0.16 ). Effects ranged from -0.84 to 1.28 , with a median of 0.02 , and the heterogeneity statistic again reached significance, $Q(23)=$ $40.37, p=.01$. The diagnostic features of EDNOS accounted for a significant proportion of effect size heterogeneity in a mixed effects ANOVA, $Q(2)=7.36, p=.03$. Specifically, there was a trend for BED to score lower on general psychopathology than heterogeneously defined EDNOS groups $(d=-0.13, p=.06)$. However, BED did not differ significantly from EDNOS groups in which participants met all criteria for BED except binge frequency $(d=0.26, p=.14)$, nor did BED differ significantly from partial BED groups who missed at least two of the BED diagnostic criteria ( $d=0.16, p=.19)$. With regard to the remaining putative moderators, studies using structured interviews did not differ from studies using unstructured interviews or self-report measures, $Q(1)=2.71, p=.10$, nor did studies using patient versus non- patient samples, $Q(1)=0.13, p=.72$. Finally, mean participant age, $Q(1)=1.63, p=.20$, was not a significant predictor of effect size.

\section{Investigation of Publication Bias}

Because neither AN nor BED differed significantly from EDNOS on eating pathology, general psychopathology, or physical health, publication bias did not represent a plausible explanation for the findings of those analyses. However, we did investigate the possibility that a bias favoring the publication of significant results accounted for the $\mathrm{BN}$ findings by evaluating publication status (published vs. unpublished) as a moderator variable and also by calculating Orwin's fail-safe $N$ (the number of studies with a Cohen's $d$ of 0 that would need to be added to the meta-analysis to bring the overall effect size to a negligible level, set to an absolute value of 0.10 in this case; Orwin, 1983). Moderator analyses indicated that effect sizes did not differ by publication status for either eating pathology, $Q(1)=0.20, p=$ .65 , or general psychopathology, $Q(1)=0.68, p=.41$. The fail-safe $N$ was 208 studies for eating pathology and 51 studies for general psychopathology, suggesting that these two findings would be relatively robust to file drawer discoveries. In contrast, the fail-safe $N$ for the BN physical health meta-analysis was only 12 studies, and publication status could not be investigated as a moderator because only published studies reported effect sizes for physical health.

\section{Discussion}

Approximately 40\% (Button et al., 2005; Ricca et al., 2001) to $60 \%$ (Fairburn et al., 2007; Martin et al., 2000; Nollet \& Button, 2005; Turner \& Bryant-Waugh, 2004) of individuals with eating disorders do not fulfill diagnostic criteria for the officially recognized $D S M-I V$ eating disorders and are therefore given the residual EDNOS diagnosis. Our meta-analysis examined the differences in EDNOS versus $\mathrm{AN}, \mathrm{BN}$, and BED to inform potential improvements to eating disorder classification. Results demonstrate that whereas EDNOS did not differ significantly from AN or BED in terms of eating pathology or general psychopathology, individuals with BN scored significantly higher than individuals with EDNOS on measures of eating $(d=0.39)$ and general $(d=0.19)$ psychopathology. In contrast, EDNOS exhibited significantly poorer physical health than $\mathrm{BN}(d=-0.18)$ but did not differ from AN in this regard.

\section{Is EDNOS a Clinically Significant Eating Disorder?}

Overall, despite its perceived subclinical nosological status in $D S M-I V$, EDNOS did not exhibit large differences in eating and general psychopathology compared with AN and BED. The nonsignificant differences between AN and EDNOS observed in our meta-analysis can be integrated with the findings of recent taxometric analyses suggesting that AN represents the severe end of a continuum that is dimensional with normal eating behavior (Williamson et al., 2002). Within a continuum model, EDNOS may lie closer to AN, with restrained eaters and chronic dieters lying between cases and noncases. In contrast, significant differences between EDNOS and $\mathrm{BN}$ support findings that $\mathrm{BN}$ may represent 
Table 6

Individual Effect Sizes for Studies Comparing Eating Disorder Not Otherwise Specified (EDNOS) With Bulimia Nervosa (BN)

\begin{tabular}{|c|c|c|c|c|c|c|c|c|c|c|c|}
\hline \multirow[b]{3}{*}{ Author (Year) } & \multirow[b]{3}{*}{$N$} & \multicolumn{4}{|c|}{ Moderator variables } & \multirow{2}{*}{\multicolumn{2}{|c|}{ Eating pathology }} & \multirow{2}{*}{\multicolumn{2}{|c|}{$\begin{array}{c}\text { General } \\
\text { psychopathology }\end{array}$}} & \multirow{2}{*}{\multicolumn{2}{|c|}{ Physical health }} \\
\hline & & \multirow{2}{*}{$\begin{array}{l}\text { EDNOS group } \\
\text { comparison }\end{array}$} & \multirow{2}{*}{$\begin{array}{l}\text { Patient } \\
\text { sample }\end{array}$} & \multirow{2}{*}{$\begin{array}{l}\text { Structured } \\
\text { interview }\end{array}$} & \multirow{2}{*}{$\begin{array}{l}\text { Mean } \\
\text { age }\end{array}$} & & & & & & \\
\hline & & & & & & $d(S E)$ & $p$ & $d(S E)$ & $p$ & $d(S E)$ & $p$ \\
\hline Abraham et al. (2005) & 119 & Heterogeneous & 1 & 0 & 18.90 & & & & & $-0.16(0.24)$ & .52 \\
\hline Abraham et al. (2006) & 119 & Heterogeneous & 1 & 0 & 20.85 & $-0.39(0.31)$ & .21 & & & $-0.41(0.23)$ & .08 \\
\hline Alvarez-Rayon et al. (2004) & 224 & Heterogeneous & 1 & 0 & 19.90 & $0.44(0.14)$ & .00 & & & & \\
\hline Andersen et al. (2001) & 141 & Heterogeneous & 1 & 0 & & $0.79(0.18)$ & .00 & $0.25(0.17)$ & .14 & & \\
\hline Bailey (2000) & 34 & Heterogeneous & 1 & 0 & 24.29 & $0.15(0.36)$ & .67 & $0.15(0.36)$ & .67 & & \\
\hline Bara-Carril et al. (2004) & 45 & Partial BN & 1 & 0 & 30.00 & $0.22(0.37)$ & .57 & & & & \\
\hline Bean et al. (2005) & 103 & Heterogeneous & 1 & 0 & 26.88 & & & $0.29(0.26)$ & .27 & & \\
\hline Ben-Tovim et al. (2001) & 125 & Heterogeneous & 1 & 1 & 23.77 & $-0.34(0.20)$ & .08 & & & & \\
\hline Beumont et al. (1993) & 66 & Heterogeneous & 1 & 0 & 22.58 & $0.56(0.26)$ & .03 & & & & \\
\hline Binford and La Grange (2005) & 56 & Purging disorder & 1 & 0 & 16.55 & $0.56(0.29)$ & .05 & $0.16(0.31)$ & .60 & $0.22(0.33)$ & .51 \\
\hline Bjorck et al. (2003) & 605 & Heterogeneous & 1 & 1 & 24.90 & & & $0.16(0.08)$ & .06 & & \\
\hline Blinder et al. (2006) & 1,480 & Heterogeneous & 1 & 0 & 24.10 & & & $0.01(0.17)$ & .95 & & \\
\hline Boyd et al. (2005) & 56 & Heterogeneous & 1 & 0 & 20.39 & $0.69(0.29)$ & .02 & $0.31(0.28)$ & .26 & $0.18(0.31)$ & .57 \\
\hline Broberg et al. (2001) & 119 & Heterogeneous & 1 & 0 & 21.30 & $0.45(0.19)$ & .02 & & & & \\
\hline \multirow[t]{2}{*}{ Bunnell et al. (1992) } & 54 & Heterogeneous & 1 & 0 & 15.41 & $0.73(0.35)$ & .04 & & & & \\
\hline & & Partial BN & 1 & 0 & 15.41 & $0.77(0.39)$ & .05 & & & & \\
\hline Button et al. (2005) & 117 & Heterogeneous & 1 & 0 & 26.30 & $0.03(0.23)$ & .90 & & & $-0.16(0.21)$ & .44 \\
\hline Carlat et al. (1997) & 105 & Heterogeneous & 1 & 0 & 27.55 & $0.08(0.20)$ & .70 & $0.42(0.26)$ & .11 & & \\
\hline Casasnovas et al. (2007) & 160 & Heterogeneous & 1 & 0 & 22.63 & $0.47(0.16)$ & .00 & $-0.05(0.16)$ & .75 & & \\
\hline Clinton and Glant (1992) & 73 & Heterogeneous & 1 & 0 & 24.74 & $0.78(0.33)$ & .02 & $-0.10(0.39)$ & .79 & $-0.38(0.33)$ & .25 \\
\hline Clinton and Norring (1999) & 334 & Heterogeneous & 1 & 0 & 22.50 & $0.79(0.12)$ & .00 & & & & \\
\hline Clinton and Norring (2005) & 433 & Heterogeneous & 1 & 0 & 24.50 & $0.31(0.10)$ & .00 & $0.10(0.10)$ & .31 & & \\
\hline Corbridge and Bell (1996) & 63 & Heterogeneous & 1 & 0 & & $-1.11(0.60)$ & .07 & $0.06(0.66)$ & .93 & & \\
\hline \multirow{2}{*}{ Crow et al. (2002) } & 236 & Heterogeneous & 0 & 1 & 31.01 & $0.62(0.15)$ & .00 & $0.33(0.17)$ & .05 & & \\
\hline & & Partial BN & 0 & 1 & 31.01 & $0.58(0.17)$ & .00 & $0.47(0.19)$ & .02 & & \\
\hline Cumella et al. (1999) & 115 & Heterogeneous & 1 & 0 & 16.03 & & & $0.29(0.20)$ & .14 & & \\
\hline Cumella et al. (2000) & 384 & Heterogeneous & 1 & 0 & 27.00 & & & $0.05(0.11)$ & .65 & & \\
\hline Diaz et al. (2003) & 72 & Heterogeneous & 0 & 1 & 18.02 & $0.75(0.24)$ & .00 & & & & \\
\hline Durham (1990) & 33 & Heterogeneous & 1 & 0 & 30.16 & $-0.82(0.40)$ & .04 & $-0.08(0.44)$ & .85 & & \\
\hline Edwin and Andersen (1990) & 40 & Heterogeneous & 1 & 0 & 26.36 & $0.74(0.38)$ & .05 & & & & \\
\hline Ekeroth et al. (2003) & 111 & Heterogeneous & 1 & 1 & 15.66 & & & $0.79(0.24)$ & .00 & & \\
\hline Ekeroth et al. (2004) & 72 & Heterogeneous & 1 & 0 & 21.60 & & & $0.23(0.24)$ & .34 & & \\
\hline Fairburn et al. (2005) & 94 & Heterogeneous & 0 & 1 & 19.56 & $0.93(0.27)$ & .00 & & & & \\
\hline Fairburn et al. (2007) & 162 & Heterogeneous & 1 & 1 & 25.88 & $0.28(0.16)$ & .09 & $0.00(0.38)$ & 1.00 & & \\
\hline Favaro and Santonastaso & & & & & & & & & & & \\
\hline (1997) & 287 & Heterogeneous & 1 & 0 & 24.39 & & & $0.36(0.18)$ & .04 & & \\
\hline Fitzgibbon et al. (2003) & 287 & Heterogeneous & 1 & 0 & 31.87 & $-0.98(0.17)$ & .00 & $0.78(0.16)$ & .00 & & \\
\hline & & Partial BN & 1 & 0 & 31.87 & $-0.53(0.14)$ & .00 & $0.36(0.13)$ & .01 & & \\
\hline Fornari et al. (1994) & 53 & Heterogeneous & 1 & 0 & 21.47 & & & $0.36(0.31)$ & .24 & & \\
\hline Fullerton et al. (1995) & 596 & Heterogeneous & 1 & 0 & 24.51 & & & $0.20(0.11)$ & .06 & & \\
\hline Garfinkel et al. (1995) & 90 & $\begin{array}{l}\text { Low binge } \\
\text { frequency } \mathrm{BN}\end{array}$ & 0 & 1 & 36.70 & $0.15(0.31)$ & .64 & $0.33(0.62)$ & .59 & & \\
\hline Gerlinghoff et al. (1998) & 78 & Heterogeneous & 1 & 0 & 23.53 & $0.34(0.36)$ & .33 & $0.18(0.36)$ & .62 & & \\
\hline Ghadirian et al. (1999) & 178 & Heterogeneous & 1 & 0 & 27.84 & & & $0.52(0.25)$ & .04 & & \\
\hline Gleaves and Eberenz (1995) & 35 & Heterogeneous & 1 & 0 & 26.50 & $0.38(0.41)$ & .36 & $0.12(0.40)$ & .77 & & \\
\hline Gleaves et al. (1998) & 173 & Heterogeneous & 1 & 0 & 24.56 & $1.27(0.17)$ & .00 & & & & \\
\hline Glorio et al. (2000) & 138 & Heterogeneous & 1 & 0 & 18.54 & & & & & $0.68(0.70)$ & .33 \\
\hline Godt (2002) & 128 & Heterogeneous & 1 & 1 & 23.39 & & & $0.05(0.21)$ & .81 & & \\
\hline Godt (2008) & 407 & Heterogeneous & 1 & 1 & 23.80 & & & $0.10(0.12)$ & .39 & & \\
\hline Goebel et al. (1999) & 81 & Heterogeneous & 1 & 0 & 26.48 & $0.37(0.38)$ & .33 & $0.72(0.57)$ & .21 & $-0.19(0.24)$ & .44 \\
\hline Griffiths et al. (1999) & 53 & Heterogeneous & 1 & 0 & 19.18 & $0.01(0.28)$ & .97 & & & & \\
\hline Grilo et al. (2007) & 92 & Heterogeneous & 1 & 1 & 31.35 & & & $0.07(0.24)$ & .79 & & \\
\hline Hasler et al. (2004) & 59 & Heterogeneous & 1 & 1 & 27.45 & & & $-0.65(0.30)$ & .03 & $-0.65(0.30)$ & .03 \\
\hline Joyce et al. (1990) & 25 & Heterogeneous & 1 & 0 & 29.20 & $0.27(0.53)$ & .61 & $-1.36(0.47)$ & .00 & $-0.51(0.61)$ & .41 \\
\hline Keel et al. (2001) & 54 & Purging disorder & 0 & 1 & 23.40 & $0.43(0.28)$ & .13 & $0.12(0.28)$ & .68 & & \\
\hline Keel et al. (2005) & 76 & Purging disorder & 0 & 0 & 25.10 & $0.42(0.23)$ & .08 & $0.19(0.35)$ & .58 & & \\
\hline Keel et al. (2007) & 57 & Purging disorder & 0 & 1 & 22.30 & $0.42(0.29)$ & .15 & $0.16(0.39)$ & .67 & & \\
\hline Kovacs et al. (2002) & 572 & Heterogeneous & 1 & 1 & & $-0.01(0.13)$ & .96 & & & & \\
\hline & & Partial BN & 1 & 1 & & $0.25(0.15)$ & .09 & & & & \\
\hline Krug et al. (2008) & 78 & Partial BN & 1 & 0 & 23.80 & $0.52(0.23)$ & .03 & $0.20(0.30)$ & .52 & & \\
\hline Kurth et al. (1995) & 56 & Heterogeneous & 0 & 1 & 17.70 & $1.10(0.44)$ & .01 & & & & \\
\hline
\end{tabular}


Table 6 (continued)

\begin{tabular}{|c|c|c|c|c|c|c|c|c|c|c|c|}
\hline \multirow[b]{3}{*}{ Author (Year) } & \multirow[b]{3}{*}{$N$} & \multicolumn{4}{|c|}{ Moderator variables } & \multirow{2}{*}{\multicolumn{2}{|c|}{ Eating pathology }} & \multirow{2}{*}{\multicolumn{2}{|c|}{$\begin{array}{c}\text { General } \\
\text { psychopathology }\end{array}$}} & \multirow{2}{*}{\multicolumn{2}{|c|}{ Physical health }} \\
\hline & & \multirow[b]{2}{*}{$\begin{array}{l}\text { EDNOS group } \\
\text { comparison }\end{array}$} & \multirow[b]{2}{*}{$\begin{array}{l}\text { Patient } \\
\text { sample }\end{array}$} & \multirow[b]{2}{*}{$\begin{array}{l}\text { Structured } \\
\text { interview }\end{array}$} & \multirow[b]{2}{*}{$\begin{array}{l}\text { Mean } \\
\text { age }\end{array}$} & & & & & & \\
\hline & & & & & & $d(S E)$ & $p$ & $d(S E)$ & $p$ & $d(S E)$ & $p$ \\
\hline Le Grange et al. (2004) & 72 & $\begin{array}{l}\text { Low binge } \\
\text { frequency } \mathrm{BN}\end{array}$ & 1 & 1 & 16.19 & $0.19(0.25)$ & .43 & $0.11(0.24)$ & .64 & $-0.22(0.27)$ & .40 \\
\hline \multirow[t]{3}{*}{ Le Grange et al. (2006) } & 195 & $\begin{array}{l}\text { Low binge } \\
\text { frequency BN }\end{array}$ & 0 & 1 & 25.70 & $-0.07(0.23)$ & .75 & & & & \\
\hline & & Purging disorder & 0 & 1 & 25.70 & $0.26(0.20)$ & .18 & & & & \\
\hline & & Partial BN & 0 & 1 & 25.70 & $-0.01(0.16)$ & .93 & $0.17(0.16)$ & .28 & & \\
\hline Lee et al. (1998) & 28 & Heterogeneous & 1 & 0 & 21.50 & $0.90(0.44)$ & .04 & & & & \\
\hline Lee et al. (2002) & 111 & Heterogeneous & 1 & 1 & 23.46 & $0.48(0.22)$ & .03 & & & & \\
\hline Lee et al. (2003) & 29 & Heterogeneous & 1 & 1 & 26.69 & $0.62(0.38)$ & .10 & $0.43(0.38)$ & .25 & & \\
\hline Levine et al. (2007) & 24 & Heterogeneous & 1 & 1 & 21.80 & & & & & $0.02(0.43)$ & .96 \\
\hline Maroñon et al. (2004) & 40 & Heterogeneous & 1 & 0 & 22.21 & & & $0.56(0.36)$ & .12 & & \\
\hline \multirow[t]{2}{*}{ Martin et al. (2000) } & 117 & Heterogeneous & 1 & 1 & 24.40 & $0.79(0.23)$ & .00 & $-0.09(0.22)$ & .67 & & \\
\hline & & Partial BN & 1 & 1 & 24.40 & $0.21(0.27)$ & .43 & $-0.29(0.27)$ & .27 & & \\
\hline McDermott et al. (2006) & 60 & Heterogeneous & 1 & 1 & 14.50 & & & $-0.01(0.31)$ & .99 & & \\
\hline Milos et al. (2003) & 171 & Heterogeneous & 0 & 1 & 27.38 & & & $0.30(0.22)$ & .16 & & \\
\hline Milos et al. (2004) & 201 & Heterogeneous & 0 & 1 & 23.97 & & & $0.10(0.24)$ & .68 & & \\
\hline Mizes et al. (2000) & 154 & Heterogeneous & 1 & 0 & 25.90 & $0.19(0.17)$ & .25 & & & & \\
\hline Moor et al. (2004) & 42 & Heterogeneous & 1 & 0 & 21.30 & $0.07(0.31)$ & .82 & $-0.09(0.31)$ & .76 & & \\
\hline Moreno and Thelen (1993) & 47 & Partial BN & 0 & 0 & & $0.82(0.31)$ & .01 & & & & \\
\hline Nevonen and Broberg (2001) & 168 & Heterogeneous & 1 & 1 & 20.90 & $0.62(0.16)$ & .00 & & & & \\
\hline Nollett and Button (2005) & 157 & Heterogeneous & 1 & 1 & 27.00 & $0.28(0.18)$ & .11 & $0.18(0.17)$ & .30 & & \\
\hline \multirow[t]{2}{*}{ Noma et al. (2006) } & 43 & $\begin{array}{l}\text { Heterogeneous } \\
\text { Low binge }\end{array}$ & 1 & 0 & 25.74 & $2.47(0.76)$ & .00 & & & & \\
\hline & & frequency $\mathrm{BN}$ & 1 & 0 & 25.74 & $0.61(0.94)$ & .52 & & & & \\
\hline Orbitello et al. (2006) & 84 & Heterogeneous & 0 & 1 & 42.00 & $1.01(0.35)$ & .00 & & & & \\
\hline Panagiotopoulos et al. (2000) & 33 & Heterogeneous & 1 & 0 & 14.88 & $-0.21(0.66)$ & .75 & & & $0.02(0.41)$ & .96 \\
\hline Probst et al. (1995) & 163 & Heterogeneous & 1 & 0 & 24.00 & $0.42(0.18)$ & .02 & & & & \\
\hline Resch et al. (2004) & 14 & Partial BN & 0 & 0 & 25.46 & & & & & $0.07(0.88)$ & .94 \\
\hline \multirow[t]{2}{*}{ Ricca et al. (2001) } & 126 & Heterogeneous & 1 & 1 & 23.24 & $0.93(0.26)$ & .00 & $0.60(0.25)$ & .02 & & \\
\hline & & Partial BN & 1 & 1 & 23.24 & $0.33(0.20)$ & .10 & $0.19(0.20)$ & .34 & & \\
\hline Ro et al. (2005) & 62 & Heterogeneous & 1 & 1 & 29.70 & & & $0.00(0.27)$ & 1.00 & & \\
\hline Salvemini et al. (2000) & 223 & Heterogeneous & 1 & 1 & 25.12 & $0.40(0.14)$ & .01 & $0.05(0.14)$ & .71 & & \\
\hline Schaefer et al. (1998) & 65 & Heterogeneous & 1 & 0 & 25.60 & $0.16(0.28)$ & .59 & & & & \\
\hline Schork et al. (1994) & 36 & Heterogeneous & 1 & 0 & & & & $0.49(0.35)$ & .16 & & \\
\hline Shafran et al. (2004) & 42 & Heterogeneous & 1 & 0 & 29.09 & $0.45(0.35)$ & .20 & $0.21(0.35)$ & .56 & & \\
\hline Sherwood et al. (2000) & 52 & Partial BN & 0 & 1 & 19.28 & $0.72(0.29)$ & .02 & & & & \\
\hline Solenberger (2001) & 65 & Heterogeneous & 1 & 0 & 20.60 & $-0.02(0.25)$ & .93 & & & & \\
\hline Spindler and Milos (2007) & 193 & Heterogeneous & 0 & 1 & 28.78 & $0.36(0.18)$ & .04 & & & & \\
\hline Stice et al. (1998) & 160 & Partial BN & 0 & 1 & 15.00 & $0.63(0.25)$ & .01 & $0.47(0.25)$ & .06 & & \\
\hline Thurfjell et al. (2003) & 114 & Heterogeneous & 1 & 1 & 15.51 & $0.61(0.23)$ & .01 & & & & \\
\hline Tobin et al. (1997) & 270 & Partial BN & 1 & 0 & 25.71 & $0.17(0.20)$ & .40 & $-0.04(0.21)$ & .83 & & \\
\hline Troop et al. (2000) & 40 & Heterogeneous & 1 & 0 & 29.34 & $0.51(0.42)$ & .22 & & & & \\
\hline Turner and Bryant-Waugh & 179 & Heterogeneous & 1 & 1 & 27.03 & $0.90(0.18)$ & .00 & & & & \\
\hline \multicolumn{12}{|l|}{ Vandereycken and Pieters } \\
\hline Vanderlinden et al. (1993) & 40 & Heterogeneous & 1 & 0 & 24.30 & $0.59(0.29)$ & .10 & $0.00(0.35)$ & $\begin{array}{l}.20 \\
1.00\end{array}$ & & \\
\hline Vaz et al. (1999) & 61 & Partial BN & 1 & 1 & & $-0.07(0.27)$ & .80 & & & & \\
\hline Weltzin et al. (2007) & 46 & Heterogeneous & 1 & 0 & 25.09 & $1.16(0.33)$ & .00 & & & & \\
\hline Wildes (2003) & 20 & $\begin{array}{l}\text { Low binge } \\
\text { frequency BN }\end{array}$ & 0 & 1 & 26.30 & $0.31(0.60)$ & .61 & $0.17(0.88)$ & .85 & & \\
\hline Wilks (2006) & 20 & Heterogeneous & 1 & 0 & 23.80 & $0.12(0.52)$ & .82 & $0.03(0.52)$ & .96 & & \\
\hline Williamson et al. (1992) & 49 & Heterogeneous & 1 & 1 & & $0.56(0.32)$ & .08 & & & & \\
\hline Williamson et al. (2002) & 112 & Heterogeneous & 1 & 1 & & $-0.24(0.19)$ & .22 & & & & \\
\hline Wunderlich et al. (2004) & 56 & Heterogeneous & 1 & 0 & 21.00 & $2.50(0.38)$ & .00 & & & & \\
\hline
\end{tabular}

Note. Blank cells in the table indicate that data for those variables were missing from the original research reports. Under "Patient sample," $1=$ psychiatric patients; $0=$ nonpatients only, or both patients and nonpatients. Under "Structured interview," $1=$ eating disorder diagnoses established via structured interview; $0=$ investigators did not explicitly state that diagnoses were established via clinical interview, or investigators stated that diagnoses were established via unstructured interview or self-report questionnaire. 
Table 7

$Q$ Statistics and Effect Sizes for Bulimia Nervosa (BN) Moderator Analyses

\begin{tabular}{|c|c|c|c|c|c|c|}
\hline Moderator & $Q$ & $p$ & Moderator levels & $d$ & $S E$ & $p$ \\
\hline \multicolumn{7}{|c|}{ Eating pathology } \\
\hline \multirow[t]{4}{*}{ EDNOS subgroup } & 5.12 & .16 & Low binge frequency $\mathrm{BN}$ & 0.10 & 0.14 & .49 \\
\hline & & & Purging disorder & 0.39 & 0.11 & $<.001$ \\
\hline & & & Partial BN & 0.29 & 0.12 & .01 \\
\hline & & & Heterogeneous or other EDNOS & 0.43 & 0.07 & $<.001$ \\
\hline \multirow{2}{*}{ Structured interview } & 0.02 & .89 & Structured interview & 0.40 & 0.06 & $<.001$ \\
\hline & & & Unstructured interview or self-report & 0.38 & 0.08 & $<.001$ \\
\hline \multirow[t]{2}{*}{ Patient status } & 1.38 & .24 & Patient sample & 0.36 & 0.06 & $<.001$ \\
\hline & & & Nonpatient or mixed sample & 0.48 & 0.08 & $<.001$ \\
\hline Mean age & 4.72 & .03 & & & & \\
\hline
\end{tabular}

Note. Moderator analyses are not presented for general psychopathology or physical health because overall $Q$ statistics were not statistically significant. EDNOS = eating disorder not otherwise specified.

a latent taxon distinct from normality (Gleaves et al., 2000; Williamson et al., 2002). Although differences in psychopathology between EDNOS and BN were statistically significant, the modest size of these differences does not fully support the notion of EDNOS as a mild variant of an eating disorder. Consider that even an effect size of 0.39 (the difference between BN and EDNOS in eating pathology) is well below the average standardized mean difference in posttreatment bulimic symptoms $(0.95)$ reported in a meta-analysis of studies comparing cognitive-behavioral therapy versus no treatment for BN (Hay, Bacaltchuk, \& Stefano, 2004). Moreover, in keeping with Wonderlich, Crosby, Mitchell, and Engel's (2007) observation that different clinical validators may lead to different conclusions regarding the status and severity of eating disorder subtypes, EDNOS exhibited significantly poorer physical health than BN. Although this latter finding is based on a relatively small number of studies $(k=14)$ and could be subject to treatment-seeking bias, it underscores the potential severity of the medical complications associated with EDNOS as an important area for clinical attention and future research. In summary, the findings of the present study highlight EDNOS as a set of clinically meaningful eating disorders associated with high levels of psychiatric and general medical morbidity.

\section{The Utility of DSM-IV Diagnostic Criteria}

It is noteworthy that patterns of results differed across officially recognized diagnoses as well as EDNOS subtypes. The significant differences between $\mathrm{BN}$ and EDNOS observed in this metaanalysis are not consistent with the wholesale application of a transdiagnostic approach that would eliminate diagnostic distinctions by classifying EDNOS in the same superordinate category as the officially recognized eating disorders. Although this parsimonious model is attractive in its potential to simplify the dissemination of empirically supported psychotherapies and to clarify the ambiguous definition of eating disorder caseness (Fairburn, 2008; Fairburn \& Bohn, 2005), it could potentially cause clinicians and researchers to overlook the observed differences between full and partial syndrome cases. Indeed, taken together with existing literature indicating clear differences in treatment outcome and mortality for AN (Steinhausen, 2002), BN (Keel, Mitchell, Miller, Davis, \& Crow, 1999), and BED (Fairburn, Cooper, Doll, Norman, \& O'Connor, 2000), our moderator analyses were more consistent with nosologic recommendations to relax certain diagnostic criteria for $\mathrm{AN}, \mathrm{BN}$, and $\mathrm{BED}$ and, potentially, to identify and extract homogeneous subtypes from within the heterogeneous EDNOS category.

Anorexia nervosa. Moderator analyses indicated that certain diagnostic features were associated with larger differences between full and partial syndrome AN. Despite recent calls for a culture-free conceptualization of AN that encompasses alternate rationales for food refusal (Lee, Ho, \& Hsu, 1993; Lee, Lee, Ngai, Lee, \& Wing, 2001), moderator analyses indicated that individuals who met all criteria for AN except fat phobia exhibited significantly lower levels of eating pathology than individuals with full syndrome AN. Although this finding was based on a modest number of studies $(k=5)$, similar effects were observed across research groups in two different non-Western societies (China and Japan), and the magnitude of the difference in psychopathology between fat-phobic and non-fat-phobic AN $(d=0.74)$ was the largest observed in the present meta-analysis. Our cross-sectional findings dovetail with prospective longitudinal data that trace a more benign naturalistic course for non-fat-phobic AN. Compared with individuals with typical AN, individuals endorsing AN without fat phobia experience higher rates of long-term remission and reduced tendency to develop bulimic symptoms over time (Lee, Chan, \& Hsu, 2003; Strober, Freeman, \& Morrell, 1999). Taken together, available data support the retention of fat phobia as a core AN diagnostic criterion in $D S M-V$. In contrast, individuals who met all diagnostic criteria for AN except amenorrhea did not differ significantly in eating pathology from individuals who met all diagnostic criteria. Although drawn from a small number of studies $(k=4)$, this finding is consistent with recommendations to drop the amenorrhea criterion (Andersen et al., 2001; Mitchell, CookMyers, \& Wonderlich, 2005) on the basis of theories that menstrual dysfunction is secondary to the substantial weight loss already required for AN. Moderator analyses similarly revealed that individuals who met all criteria for AN except the weight cutoff did not differ significantly from full AN in terms of eating pathology. The finding that individuals who restrict their food intake at slightly higher weights exhibit psychopathology commensurate with their lower-weight counterparts may stem in part from recent population increases in overweight and obesity (Hedley et al., 2004), which render diagnostically low weights increas- 
Table 8

Individual Effect Sizes for Studies Comparing Eating Disorder Not Otherwise Specified (EDNOS) With Binge Eating Disorder (BED)

\begin{tabular}{|c|c|c|c|c|c|c|c|c|c|}
\hline & & Modera & or variabl & & & Fating natho & & General & \\
\hline & & & Patient & Structured & Mean & Latming patur & & & \\
\hline Author (Year) & $N$ & EDNOS group comparison & sample & interview & age & $d(S E)$ & $p$ & $d(S E)$ & $p$ \\
\hline Adami et al. (1995) & 63 & Partial BED & 0 & 0 & 38.00 & $0.16(0.27)$ & .55 & & \\
\hline Antony et al. (1994) & 45 & Partial BED & 0 & 0 & 38.42 & $1.06(0.33)$ & .00 & $1.28(0.34)$ & .00 \\
\hline Bjorck et al. (2003) & 332 & Heterogeneous & 1 & 1 & 24.90 & & & $-0.22(0.15)$ & .16 \\
\hline Cachelin et al. (1999) & 21 & Low binge frequency BED & 0 & 1 & 31.94 & $1.18(0.47)$ & .01 & $0.16(0.44)$ & .71 \\
\hline Cartiglia (1995) & 31 & Partial BED & 0 & 1 & 20.45 & $0.30(0.36)$ & .41 & $0.06(0.36)$ & .86 \\
\hline Clinton and Norring (2005) & 224 & Heterogeneous & 1 & 0 & 24.50 & $0.11(0.19)$ & .59 & $-0.07(0.19)$ & .73 \\
\hline Crow et al. (2002) & 253 & Low binge frequency BED & 0 & 1 & 34.48 & $0.31(0.18)$ & .09 & $0.00(0.22)$ & .99 \\
\hline & & Heterogeneous & 0 & 1 & 34.48 & $0.41(0.15)$ & .01 & $-0.16(0.16)$ & .34 \\
\hline De Zwaan et al. (1994) & 63 & Partial BED & 0 & 0 & 39.37 & $0.54(0.28)$ & .05 & $-0.62(0.28)$ & .03 \\
\hline Eldredge et al. (1996) & 88 & Heterogeneous & 0 & 0 & 41.45 & $0.48(0.22)$ & .03 & & \\
\hline Favaro and Santonastaso (1997) & 118 & Heterogeneous & 1 & 0 & 25.70 & & & $0.00(0.27)$ & 1.00 \\
\hline Fitzgibbon et al. (2003) & 228 & Low binge frequency BED & 1 & 0 & 36.04 & $-0.26(0.18)$ & .16 & $0.49(0.18)$ & .01 \\
\hline & & Heterogeneous & 1 & 0 & 36.04 & $-0.21(0.16)$ & .19 & $0.01(0.16)$ & .96 \\
\hline Fontenelle et al. (2005) & 34 & Heterogeneous & 0 & 1 & 36.74 & $-0.15(0.34)$ & .66 & $-0.84(0.36)$ & .02 \\
\hline Friederich et al. (2007) & 70 & Partial BED & 1 & 1 & 44.61 & $-0.01(0.28)$ & .98 & $0.04(0.29)$ & .90 \\
\hline $\begin{array}{l}\text { Gladis, Wadden, Foster, et al. } \\
\text { (1998) }\end{array}$ & 37 & Partial BED & 0 & 0 & 41.04 & & & $0.54(0.35)$ & .12 \\
\hline $\begin{array}{l}\text { Gladis, Wadden, Vogt, et al. } \\
\text { (1998) }\end{array}$ & 41 & Partial BED & 0 & 0 & 40.90 & $0.48(0.33)$ & .15 & $0.14(0.32)$ & .66 \\
\hline Grissett and Fitzgibbon (1996) & 144 & Partial BED & 1 & 0 & 41.80 & $0.96(0.18)$ & .00 & $0.15(0.20)$ & .46 \\
\hline Kruger et al. (1996) & 23 & Partial BED & 1 & 0 & 39.08 & $0.22(0.49)$ & .65 & $0.00(0.67)$ & 1.00 \\
\hline Kuehnel and Wadden (1994) & 40 & Partial BED & 0 & 0 & 41.22 & $0.44(0.36)$ & .22 & $0.35(0.36)$ & .33 \\
\hline Martin et al. (2000) & 99 & Heterogeneous & 1 & 1 & 25.25 & $-0.37(0.29)$ & .19 & $-0.12(0.27)$ & .65 \\
\hline & & Partial BED & 1 & 1 & 25.25 & $0.09(0.38)$ & .82 & $0.05(0.38)$ & .90 \\
\hline P. M. Miller et al. (1999) & 29 & Partial BED & 0 & 0 & 48.89 & $0.84(0.39)$ & .03 & & \\
\hline Noma et al. (2006) & 27 & Heterogeneous & 1 & 0 & 27.10 & $0.21(0.54)$ & .69 & & \\
\hline Orbitello et al. (2006) & 107 & Heterogeneous & 0 & 1 & 42.00 & $-0.41(0.21)$ & .06 & & \\
\hline Raymond et al. (2002) & 98 & Partial BED & 0 & 1 & 39.52 & & & $0.07(0.21)$ & .74 \\
\hline Riva et al. (2000) & 39 & Heterogeneous & 0 & 1 & & $0.09(0.34)$ & .78 & & \\
\hline Salvemini et al. (2000) & 105 & Heterogeneous & 1 & 1 & 28.92 & $-0.44(0.21)$ & .04 & $0.00(0.21)$ & .99 \\
\hline Siervo et al. (2005) & 75 & Heterogeneous & 0 & 0 & 24.00 & $0.54(0.32)$ & .09 & & \\
\hline Striegel-Moore et al. (2000) & 88 & Partial BED & 0 & 1 & 29.31 & $0.17(0.21)$ & .44 & $0.08(0.21)$ & .70 \\
\hline Tobin et al. (1997) & 62 & Heterogeneous & 1 & 0 & 29.18 & $-0.19(0.26)$ & .46 & $-0.24(0.26)$ & .37 \\
\hline Troop et al. (2000) & 13 & Heterogeneous & 1 & 0 & 25.87 & $0.19(0.56)$ & .74 & & \\
\hline Williamson et al. (2002) & 110 & Heterogeneous & 1 & 1 & & $-0.79(0.20)$ & .00 & & \\
\hline
\end{tabular}

Note. Blank cells in the table indicate that data for those variables were missing from the original research reports. Under "Patient sample," $1=$ psychiatric patients; $0=$ nonpatients only, or both patients and nonpatients. Under "Structured interview," 1 = eating disorder diagnoses established via structured interview; 0 = investigators did not explicitly state that diagnoses were established via clinical interview, or investigators stated that diagnoses were established via unstructured interview or self-report questionnaire.

ingly difficult to achieve. As important caveats, moderator analyses examining the utility of the weight criterion were based on a small number of studies $(k=2)$ and did not converge on a new weight cutoff that could be recommended for DSM-V. Although Andersen et al. (2001) required EDNOS participants to weigh $<80 \%$ of premorbid weight, Watson and Andersen (2003) did not set a specific weight cutoff for EDNOS. Complicating matters further, a recent methodological review identified 10 distinct methods for calculating eating disorder patients' expected body weights highlighting discrepancies of up to 25 pounds in the weight at which AN would be diagnosed even under current criteria (Thomas, Roberto, \& Brownell, in press).

The partial AN subgroup in which participants missed two diagnostic criteria for $\mathrm{AN}$ is of particular interest when considering possible DSM-V revisions because three (Bunnell, Cooper, Hertz, \& Shenker, 1992; Ricca et al., 2001; Watson \& Andersen, 2003) of the seven studies comprising this group examined individuals who failed to meet both the amenorrhea and weight criterion. The finding that partial AN did not differ significantly in eating pathology from full syndrome AN suggests that it may be possible to drop the amenorrhea criterion and increase the weight criterion simultaneously without jeopardizing the homogeneity of the AN category. A recent study of eating disorder patients found that revising both of these diagnostic criteria concurrently could go far to reduce the overcrowding of the EDNOS category by reappropriating $15.5 \%$ of eating disorder patients from EDNOS to AN (Thaw, Williamson, \& Martin, 2001).

Bulimia nervosa. Although the omnibus $Q$ statistic for the diagnostic criteria moderator analysis was not statistically significant, we examined differential effects for EDNOS subgroups on an exploratory basis. Analyses revealed that individuals with BN scored significantly higher on measures of eating pathology than individuals with purging disorder, underscoring the importance of requiring that binge episodes be characterized by the consumption 
Table 9

Statistics and Effect Sizes for Binge Eating Disorder (BED) Moderator Analyses

\begin{tabular}{|c|c|c|c|c|c|c|}
\hline Moderator & $Q$ & $p$ & Moderator levels & $d$ & $S E$ & $p$ \\
\hline \multicolumn{7}{|c|}{ Eating pathology } \\
\hline \multirow[t]{3}{*}{ EDNOS subgroup } & 9.85 & .01 & Low binge frequency BED & 0.28 & 0.32 & .37 \\
\hline & & & Partial BED & 0.46 & 0.12 & $<.001$ \\
\hline & & & Heterogeneous or other EDNOS & -0.07 & 0.12 & .58 \\
\hline \multirow[t]{2}{*}{ Structured interview } & 3.64 & .06 & Structured interview & -0.02 & 0.13 & .91 \\
\hline & & & Unstructured interview or self-report & 0.33 & 0.12 & .01 \\
\hline \multirow[t]{2}{*}{ Patient status } & 5.45 & .02 & Patient sample & -0.07 & 0.15 & .67 \\
\hline & & & Nonpatient or mixed sample & 0.35 & 0.09 & $<.001$ \\
\hline \multirow[t]{2}{*}{ Mean age } & 1.89 & .17 & & & & \\
\hline & & & General psychopathology & & & \\
\hline \multirow[t]{3}{*}{ EDNOS subgroup } & 7.36 & .03 & Low binge frequency BED & 0.26 & 0.18 & .14 \\
\hline & & & Partial BED & 0.16 & 0.12 & .19 \\
\hline & & & Heterogeneous or other EDNOS & -0.13 & 0.07 & .06 \\
\hline \multirow[t]{2}{*}{ Structured interview } & 2.71 & .10 & Structured interview & -0.08 & 0.07 & .23 \\
\hline & & & Unstructured interview or self-report & 0.15 & 0.12 & .22 \\
\hline \multirow[t]{2}{*}{ Patient status } & 0.13 & .72 & Patient sample & 0.01 & 0.06 & .83 \\
\hline & & & Nonpatient or mixed sample & 0.07 & 0.13 & .62 \\
\hline Mean age & 1.63 & .20 & & & & \\
\hline
\end{tabular}

Note. Moderator analyses are not presented for physical health because no studies were identified that examined physical health in individuals with eating disorder not otherwise specified (EDNOS) versus BED.

of objectively large quantities of food. In contrast, the twice weekly binge frequency criterion did not reliably distinguish between BN and EDNOS on measures of eating pathology. Although statistical power to detect small effects in this analysis was limited because of small sample size $(k=5)$, findings can confidently be interpreted as evidence that differences between individuals who meet all diagnostic criteria for $\mathrm{BN}$ versus individuals who meet all criteria except binge frequency are not large, thus highlighting the binge frequency criterion as a potential candidate for revision in $D S M-V$. Nonsignificant differences between full syndrome $\mathrm{BN}$ and low binge frequency $\mathrm{BN}$ are consistent with findings from a behavioral genetic study reporting that risk for binge eating in one co-twin did not decrease substantially when the other co-twin reported binge eating less than twice per week (Sullivan, Bulik, \& Kendler, 1998). Unfortunately, studies included in the present meta-analysis did not converge on a clear threshold that could be recommended for use in $D S M-V$. Required binge frequencies for partial syndrome BN ranged from once per week (Le Grange et al., 2004, 2006) to once per month (Wildes, 2003) or less (Garfinkel et al., 1995; Noma et al., 2006). Available data suggest that relaxing the $\mathrm{BN}$ binge frequency criterion would have a relatively small impact on the proportion of individuals currently diagnosed with EDNOS. Two recent simulations found that relaxing this criterion to once per week (Fairburn et al., 2007) or omitting it entirely (Thaw et al., 2001) would reappropriate only $4 \%-5 \%$ of the total pool of eating disorder patients from EDNOS to BN.

Binge eating disorder. BED findings echoed $\mathrm{BN}$ findings in questioning the retention of the twice weekly binge frequency criterion in $D S M-V$. Specifically, individuals with BED did not differ significantly on measures of eating pathology or general psychopathology from individuals who met all criteria for BED except binge frequency. Again, statistical power was limited by the small number of studies $(k=3)$ available for this analysis. Studies did not converge on an optimal binge frequency for use in $D S M-V$ because frequencies for partial syndrome BED ranged from 1 day per week (Cachelin et al., 1999) to 1 day per month (Crow et al., 2002) or less (Fitzgibbon et al., 2003). In the absence of data, the potential impact of altering the binge frequency criterion on the prevalence of BED versus partial syndrome BED remains unknown.

\section{Recommendations for DSM}

There is clear evidence from our meta-analysis that specific diagnostic criteria for $\mathrm{AN}, \mathrm{BN}$, and BED could be revised without sacrificing the homogeneity of eating disorder diagnostic categories. Revising these criteria would likely reallocate a substantial proportion of individuals from the heterogeneous EDNOS category to the more homogeneous $\mathrm{AN}, \mathrm{BN}$, and BED diagnoses, where they could be recruited into controlled treatment trials, classified as cases in epidemiological studies, and empirically studied in greater detail. However, there is also considerable evidence that EDNOS - even in its more heterogeneous forms-is of comparable severity with the officially recognized eating disorders. Therefore, we recommend a possible two-tiered approach to eating disorder classification in future versions of DSM. The first tier of eating disorders could include revised versions of AN (with a more lenient weight criterion and without amenorrhea), BN (with a more lenient binge frequency requirement), and BED (also with a more lenient binge frequency requirement). Given the likelihood that a substantial proportion of individuals with EDNOS would retain this residual diagnosis even after the revision of clinically irrelevant criteria (Fairburn et al., 2007; Thaw et al., 2001), a second tier of eating disorders could be defined. The second tier would be reserved for uniquely defined eating disorders that are of clinically significant concern but that (a) have received somewhat less research attention, and (b) clearly differ from first-tier eating disorders on important clinical validators 
such as level of eating pathology, treatment outcome, or longitudinal course. This approach would parallel, for example, the inclusion of dysthymic disorder alongside major depressive disorder in the DSM-IV mood disorders category. Mood disorders provide a good analogy here because there is no assumption that the greater symptom acuity of major depressive disorder somehow renders it a "truer" or "more severe" mood disorder than dysthymia, which is defined in part by greater chronicity. In other words, significant differences across a matrix of clinical validators should assist us in demarcating the boundaries between diagnostic categories, but differences on a single validator should not be interpreted as reflecting greater overall severity in one disorder versus another (Wonderlich et al., 2007). To that end, inclusion in the second tier of eating disorder diagnoses should be predicated on meeting a minimum standard of empirical study and clinical impairment above and beyond mere inclusion in the DSM-IV list of example EDNOS presentations. On the basis of our findings, both purging disorder (Keel et al., 2005; Keel, Wolfe, Liddle, De Young, \& Jimerson, 2007) and non-fat-phobic AN (Lee et al., 1993, 2001) would be prime candidates for inclusion in the second tier. In contrast, we did not identify any studies examining individuals who solely engage in chewing and spitting in the absence of more traditional compensatory behaviors; thus, this condition should probably not qualify for inclusion in the second tier as a standalone syndrome, but it should rather remain in the EDNOS category. The combined approach of relaxing current criteria and identifying unique disorders would reduce the prevalence of EDNOS relative to $\mathrm{AN}, \mathrm{BN}$, and $\mathrm{BED}$, thus preserving the residual category for those atypical cases for which it was originally intended.

\section{The Next Generation of Nosological Research}

In addition to ascertaining the magnitude of differences between EDNOS and officially recognized eating disorders, a secondary purpose of the present study was to identify theoretical and methodological limitations of the EDNOS literature to inform the next generation of nosological research. The following six recommendations are offered to enhance the marginal utility of future contributions.

Clear identification of clinical characteristics. The most important methodological limitation of the 125 studies included in the meta-analysis was that nearly half did not provide any information on the eating disorder features of EDNOS participants. It was unclear from many articles whether individuals in the EDNOS group met criteria for established EDNOS subtypes or whether they exhibited new and unique variants of eating pathology. This lack of conceptual clarity renders findings of individual studies difficult to interpret because the specific clinical group(s) to which results might generalize remains unknown. Therefore, the existing knowledge base will benefit most from studies that unlock this "black box" by clearly delineating the eating disorder symptoms of EDNOS subgroups to (a) evaluate the clinical utility of specific diagnostic criteria for AN and BN (e.g., Le Grange et al., 2006), or (b) explore the distinctiveness of newly proposed eating disorders (e.g., Napolitano, Head, Babyak, \& Blumenthal, 2001). Of note, many of the research reports included in the present meta-analysis emerged from well-characterized, large-scale databases that could potentially provide a wealth of secondary data analyses along these lines.

Adherence to a provisional nomenclature. The research reports included in the present meta-analysis referred to EDNOS by more than 30 different names. For example, BN-like eating disorders characterized by the presence of purging behaviors in the absence of objective binge episodes were variously called compensatory eating disorder (Tobin, Griffing, \& Griffing, 1997), subjective bulimia nervosa (Keel et al., 2001), purging disorder (Keel et al., 2005, 2007), and EDNOS-P (Binford \& Le Grange, 2005). In contrast, the term subthreshold BED (Fitzgibbon et al., 2003; Gladis, Wadden, Vogt, et al., 1998; Striegel-Moore et al., 2000) became a homonym for multiple permutations of meeting some but not all diagnostic criteria for BED. Although each of these labels is descriptive and represents positive efforts to delineate the clinical characteristics of EDNOS subtypes, nomenclatural inconsistencies obstruct comparisons across studies. In future studies, investigators should attempt to adhere to the EDNOS subtyping nomenclature established in prior literature, however provisional, because consistent labeling schemes will facilitate crossstudy comparisons. An ideal naming scheme would feature labels that are as descriptive as possible without becoming cumbersomely long, and it would include the names of key symptoms that are either highly characteristic of that subgroup, or, alternatively, symptoms that keep the group from meeting full criteria for an established disorder. Under these suggested guidelines, referents such as non-fat-phobic AN, nonamenorrheic AN, and high weight AN would be ideal for AN-like EDNOS variants; and purging disorder and night eating syndrome would be ideal for newly characterized disorders. Acronyms that are not readily interpretable (i.e. EDNOS-P, ANXW) should be avoided.

Rigorous diagnostic assessment. Fewer than half of the studies included in the present meta-analysis reported having used structured clinical interviews to establish eating disorder diagnoses. This is worrisome in light of research demonstrating that clinicians do not always adhere to DSM criteria when they confer diagnoses, resulting in poor to fair agreement between structured interviewbased and clinician-based diagnoses (P. R. Miller, Dasher, Collins, Griffiths, \& Brown, 2001; Shear et al., 2000). In the context of the present meta-analysis, moderator analyses revealed a trend for studies using structured interviews to report smaller differences in eating pathology between EDNOS and BED than studies using unstructured interviews or self-report measures. It is possible that this pattern of findings stems from the differential construction of the ambiguous boundary between EDNOS and nonpathological eating behavior in clinical versus nonclinical settings. Because the $D S M-I V$ merely cites examples of clinical presentations that are eligible for the EDNOS label rather than providing explicit inclusion and exclusion criteria, conferring this diagnosis in clinical practice is a highly subjective process. Only a handful of studies included in the present meta-analysis described having applied exclusion criteria to the EDNOS group by requiring that patients meet specific operational definitions of EDNOS. For example, Crow et al. (2002) diagnosed patients with "partial AN" only if they either (a) met all criteria for AN except weighing less than $90 \%$ of expected body weight, or (b) met full criteria for AN in the past 12 months. Similarly, Binford and Le Grange (2005) diagnosed patients with "EDNOS-P" only if they had purged at least once per week in the past 6 months in the absence of objective 
binge episodes. In light of the trend we observed for studies using structured interviews to obtain smaller effects, it is interesting that the majority of studies that created and utilized operational definitions of EDNOS also cited the use of structured interviews to confer diagnoses (e.g., Binford \& Le Grange, 2005; Crow et al., 2002; Fairburn et al., 2007; Turner \& Bryant-Waugh, 2004). Given the high rates of body dissatisfaction and disordered eating behaviors observed in community samples (Ackard, Fulkerson, \& Neumark-Sztainer, 2007; Sullivan et al., 1998), it is clearly not necessary to diagnose all individuals seeking treatment for eatingrelated difficulties with a clinically significant eating disorder. In the context of the present meta-analysis, a lack of exclusion criteria on the EDNOS diagnosis in studies relying on unstructured assessment protocols may have artificially inflated observed differences between EDNOS and BN if healthy controls were in included the EDNOS group. Alternatively, the misclassification of partial syndrome cases of $\mathrm{AN}, \mathrm{BN}$, or BED in the full syndrome group as a consequence of unreliable definitions of EDNOS could also have attenuated observed effects. Therefore, future efforts should be made to explicitly delineate inclusion criteria for EDNOS in both clinical and research settings. Valid and reliable diagnoses of $D S M-I V$ EDNOS subtypes are best derived from eating disorderspecific assessments rather than general psychiatric interviews. For example, the Eating Disorder Examination (Fairburn, Cooper, \& O'Connor, 2008), the Interview for the Diagnosis of Eating Disorders (Kutlesic, Williamson, Gleaves, Barbin, \& MurphyEberenz, 1998), and the Structured Interview for Anorexic and Bulimic Disorders (Fichter, Herpertz, Quadflieg, \& HerpertzDahlmann, 1998) thoroughly assess a wide variety of eating disorder features, such as subjective binge episodes and chewing/ spitting, which are characteristic of specific EDNOS variants but not explicitly diagnostic of AN, BN, or BED.

Attention to sample demographics. Moderator analyses demonstrated that sample characteristics other than diagnostic criteria also influenced the magnitude of observed effects. Patient samples yielded smaller discrepancies in eating pathology between BED and EDNOS than nonpatient or mixed samples. This is consistent with well-replicated findings that treatment-seeking is associated with greater psychopathology (Keel et al., 2002), which may have obfuscated any differences between EDNOS and officially recognized disorders. It is noteworthy that more than two thirds of the studies included in the meta-analysis examined exclusively patient samples. Community samples, which feature wider variability between full and partial syndrome cases, might prove especially useful for future empirical evaluation of diagnostic thresholds, such as the optimal weight cutoff for $\mathrm{AN}$ and binge frequency requirement for $\mathrm{BN}$.

Participant age represented another demographic characteristic that influenced the magnitude of observed differences between EDNOS and officially recognized disorders. Younger samples demonstrated greater discrepancies in eating pathology between $\mathrm{BN}$ and EDNOS than older samples. In contrast, younger samples demonstrated greater similarities in general psychopathology between AN and EDNOS. Differential age effects between AN and $\mathrm{BN}$ are to some extent consistent with epidemiological research indicating that $\mathrm{BN}$ may exhibit an older age of onset and a longer duration of illness (Hudson et al., 2007) than AN. It is possible that EDNOS may develop among young people as a milder variant of psychopathology for which early, less intensive interventions would prevent the subsequent onset of full-blown BN. Indeed, to the extent that $D S M-I V$ defined eating disorders do not adequately capture the differential clinical presentation of younger samples (Nicholls et al., 2000), childhood eating disorders typically focus on restricting (e.g., food avoidance emotional disorder, selective eating disorder) rather than purging behaviors (Bryant-Waugh, 2000). Multivariate modeling techniques could be utilized to ascertain the validity of distinct syndromes within this demographic segment.

Adequate statistical power. The finding that $\mathrm{BN}$ differed significantly from EDNOS with regard to eating pathology is inconsistent with recent comparisons finding no significant differences between the two groups (e.g., Binford \& Le Grange, 2005; Fairburn et al., 2007), and could be interpreted as challenging burgeoning transdiagnostic theories of eating disorders. One likely explanation for the discrepancy between our meta-analytic findings and the results of the individual studies is differential statistical power. The median sample size for BN versus EDNOS comparisons was 84 total participants, which is far fewer than the 99 participants per group necessary for $80 \%$ power to detect an effect size of 0.40 at $\alpha=.05$ in an independent samples $t$-test (Cohen, 1988). Thus, although many studies were individually underpowered to detect small effects, their combined findings revealed significant meta-analytic differences. Now that this metaanalysis has determined that differences between EDNOS and officially recognized eating disorders are relatively small, future studies could demonstrate greater statistical conclusion validity by recruiting a sufficient number of participants to detect effects of this modest magnitude. Adequate sample size is especially important for nosological research because heterogeneously defined EDNOS groups are likely to feature large intragroup variances, which could further thwart efforts to detect significant findings.

The adoption of innovative statistical techniques. To date, the EDNOS literature has relied heavily on univariate group comparisons between partial and full syndrome cases. These investigations have been fruitful in challenging the validity of $D S M-I V$ thresholds (i.e. binge frequency for $\mathrm{BN}, 85 \%$ expected body weight for AN) but are limited by their inability to nominate more appropriate thresholds, to reveal whether significant effects reflect qualitative differences in kind versus quantitative differences in degree, or to identify the ideal boundary between cases and noncases. Thus, as we move toward $D S M-V$, we encourage investigators to consider the application of alternative statistical methods that may be better suited toward the creation of a new system versus the continued critique of the old one. Multivariate techniques, such as latent class analysis (Bulik et al., 2000; StriegelMoore et al., 2005) and taxometrics (Gleaves et al., 2000; Williamson et al., 2002), have already been used to good effect along these lines, and could potentially prove even more useful if clinically relevant variables that do not overlap with extant $D S M-I V$ diagnostic criteria - such as egosyntonicity of symptoms and treatment response-were incorporated to further differentiate among groups. Nonlinear regression and receiver-operating curve analyses might also be used to generate proposals for new diagnostic thresholds. New measures designed to assess the functional impairment associated with eating disorder features (Bohn et al., 2008; Engel et al., 2006) could provide a wealth of promising assessments through which newly proposed weight and binge frequency thresholds could subsequently be validated. 


\section{Limitations of the Present Study}

The findings of this meta-analysis should be interpreted with the following caveats in mind. The first limitation is the modest statistical power to detect small effects in analyses that relied on small sample sizes. Because BED represents a relatively recent addition to the nosological scheme (APA, 1994), only 30 studies could be identified that examined its relationship to other types of EDNOS. Similarly, all three study sets contained a limited number of comparisons for certain EDNOS subtypes, such as high weight $\mathrm{AN}(k=2)$, AN without amenorrhea $(k=4)$, non-fat-phobic AN $(k=5)$, purging disorder $(k=5)$, and BN and BED with low binge frequency ( $k=5$ and $k=3$, respectively). At most, the results of small-sample moderator analyses examining specific diagnostic criteria could be interpreted as evidence that effect sizes are not large, and the generalizeability of our results may be limited. One positive feature of our analytic plan, however, is that utilizing a random (as opposed to fixed) effects approach enhances the potential generalizeability of the findings (Field, 2003; Lipsey \& Wilson, 2001). In addition, although the small sample size of specific moderator analyses may have limited the statistical power of the present meta-analysis, we hope that our quantitative review draws the field's attention to underresearched corners of the literature that are in need of additional empirical attention.

Second, interrater reliability was lower for the classification of EDNOS subgroups according to BN diagnostic criteria $(\kappa=.71)$ than for the other moderator variables. Although a kappa of .71 is considered substantial (Landis \& Koch, 1977), and coder discrepancies were each ultimately resolved through consensus, some disagreements stemmed from the limited availability of information in original research reports, which may have introduced error into the classification of EDNOS subtypes. A final limitation of the present study is that current measures of eating disorder psychopathology are based on contemporary conceptualizations of symptoms that stem in part from extensive clinical and research experience with $\mathrm{AN}$ and $\mathrm{BN}$. Thus, it is possible that effect sizes from individual studies, and, therefore, our overall meta-analysis, would be attenuated if assessments were more attuned to assessing the specific psychopathology of EDNOS cases.

\section{Summary}

A meta-analysis of 125 studies highlighted the clinical severity of EDNOS by demonstrating that individuals who receive this residual eating disorder diagnosis exhibit small to no significant differences in eating pathology, general psychopathology, and physical health compared with individuals diagnosed with officially recognized $D S M-I V$ eating disorders. Moderator analyses suggest that a combination of relaxing current criteria and carving out homogeneous NOS subtypes would be superior to a transdiagnostic solution when considering $D S M-V$ revisions. The marginal utility of future contributions to the EDNOS literature would be greatly enhanced through clearer identification of diagnostic features, adherence to a provisional nomenclature, rigorous diagnostic assessment, attention to sample demographics, enhanced statistical power, and the adoption of innovative statistical techniques. Because the high prevalence of EDNOS represents a special case of overflowing atypical categories across a wide range of psychiatric disorders, the design and implications of the current study could be adapted for evaluating the utility of other nosological categories. Diagnostic boundaries between officially recognized and NOS psychiatric disorders should ideally reflect empirical evaluation of differential symptom severity, functional impairment, and treatment response.

\section{References}

References marked with an asterisk indicate studies included in the meta-analysis.

*Abraham, S. F., Pettigrew, B., Boyd, C., \& Russell, J. (2006). Predictors of functional and exercise amenorrhoea among eating and exercise disordered patients. Human Reproduction, 21, 257-261.

*Abraham, S. F., Pettigrew, B., Boyd, C., Russell, J., \& Taylor, A. (2005). Usefulness of amenorrhea in the diagnosis of eating disorder patients. Journal of Psychosomatic Obstetrics \& Gynecology, 26, 211-215.

Ackard, D. M., Fulkerson, J. A., \& Neumark-Sztainer, D. (2007). Prevalence and utility of $D S M-I V$ eating disorder diagnostic criteria among youth. International Journal of Eating Disorders, 40, 409-417.

Ackerman, P. L., Beier, M. E., \& Boyle, M. O. (2005). Working memory and intelligence: The same or different constructs? Psychological Bulletin, 131, 30-60.

*Adami, G. F., Gandolfo, P., Bauer, B., \& Scopinaro, N. (1995). Binge eating in massively obese patients undergoing bariatric surgery. International Journal of Eating Disorders, 17, 45-50.

Alegria, M., Woo, M., Cao, Z., Torres, M., Xiao-Li, M., \& Striegel-Moore, R. (2007). Prevalence and correlates of eating disorders in Latinos in the United States. International Journal of Eating Disorders, 40, S15-S21.

Allison, K. C., Grilo, C. M., Masheb, R. M., \& Stunkard, A. J. (2005). Binge eating disorder and night eating syndrome: A comparative study of disordered eating. Journal of Consulting and Clinical Psychology, 73, 1107-1115

*Alvarez-Rayon, G., Mancilla-Diaz, J. M., Vazquez-Arevalo, R., UnikelSantoncini, C., Caballero-Romo, A., \& Mercado-Corona, D. (2004). Validity of the Eating Attitudes Test: A study of Mexican eating disorders patients. Eating \& Weight Disorders, 9, 243-248.

American Psychiatric Association. (1980). Diagnostic and statistical manual of mental disorders (3rd ed.). Washington, DC: Author.

American Psychiatric Association. (1987). Diagnostic and statistical manual of mental disorders (3rd ed., rev.). Washington, DC: Author.

American Psychiatric Association. (1994). Diagnostic and statistical manual of mental disorders (4th ed.). Washington, DC: Author.

American Psychiatric Association. (2000). Diagnostic and statistical manual of mental disorders (4th ed., text rev.). Washington, DC: Author.

*Andersen, A. E., Bowers, W. A., \& Watson, T. (2001). A slimming program for eating disorders not otherwise specified: Reconceptualizing a confusing, residual diagnostic category. Psychiatric Clinics of North America, 24, 271-280.

*Antony, M. M., Johnson, W. G., Carr-Nangle, R. E., \& Abel, J. L. (1994). Psychopathology correlates of binge eating and binge eating disorder. Comprehensive Psychiatry, 35, 386-392.

Ash, J. B., \& Piazza, E. (1995). Changing symptomatology in eating disorders. International Journal of Eating Disorders, 18, 27-38.

*Bailey, P. M. (2000). An examination of the relationship between childhood sexual abuse, dissociation, and eating disorders. Dissertation $A b-$ stracts International, 62(02), 1065B. (UMI No. 3004044)

*Bara-Carril, N., Williams, C. J., Pombo-Carril, M. G., Reid, Y., Murray, K., Aubin, S., et al. (2004). A preliminary investigation into the feasibility and efficacy of a CD-ROM-based cognitive behavioral self-help intervention for bulimia nervosa. International Journal of Eating Disorders, 35, 538-548.

*Bean, P., Maddocks, M. B., Timmel, P., \& Weltzin, T. (2005). Gender differences in the progression of co-morbid psychopathology symptoms of eating disordered patients. Eating \& Weight Disorders, 10, 168-174. 
Beck, A. T., Ward, C. H., Mendelson, M., Mock, J., \& Erbaugh, J. (1961). An inventory for measuring depression. Archives of General Psychiatry, 4, 561-571.

*Ben-Tovim, D. I., Walker, K., Gilchrist, P., Freeman, R., Kalucy, R., \& Esterman, A. (2001). Outcome in patients with eating disorders: A 5-year study. Lancet, 357, 1254-1257.

Beumont, P. J. V., Garner, D. M., \& Touyz, S. W. (1994). Diagnoses of eating or dieting disorders: What may we learn from past mistakes? International Journal of Eating Disorders, 16, 349-362.

*Beumont, P. J. V., Kopec-Schrader, E. M., Talbot, P., \& Touyz, S. W. (1993). Measuring the specific psychopathology of eating disorder patients. Australian and New Zealand Journal of Psychiatry, 27, 506-511.

*Binford, R. B., \& Le Grange, D. (2005). Adolescents with bulimia nervosa and eating disorder not otherwise specified-purging only. International Journal of Eating Disorders, 38, 157-161.

*Bjorck, C., Clinton, D., Sohlberg, S., Hallstrom, T., \& Norring, C. (2003). Interpersonal profiles in eating disorders: Ratings of SASB self-image. Psychology and Psychotherapy: Theory, Research and Practice, 76, 337-349.

*Blinder, B. J., Cumella, E. J., \& Sanathara, V. A. (2006). Psychiatric comorbidities of female inpatients with eating disorders. Psychosomatic Medicine, 68, 454-462.

Bohn, K., Doll, H. A., Cooper, Z., O'Connor, M., Palmer, R. L., \& Fairburn, C. G. (2008). The measurement of impairment due to eating disorder psychopathology. Behaviour Research and Therapy, 46, 11051110.

Borenstein, M., Hedges, L., Higgins, J., \& Rothstein, H. (2005). Comprehensive meta-analysis: Version 2.0. Englewood, NJ: Biostat.

"Boyd, C., Abraham, S., \& Kellow, J. (2005). Psychological features are important predictors of functional gastrointestinal disorders in patients with eating disorders. Scandinavian Journal of Gastroenterology, 40, 929-935.

*Broberg, A. G., Hjalmers, I., \& Nevonen, L. (2001). Eating disorders, attachment and interpersonal difficulties: A comparison between 18- to 24-year-old patients and normal controls. European Eating Disorders Review, 9, 381-396.

Bryant-Waugh, R. (2000). Overview of the eating disorders. In B. Lask \& R. Bryant-Waugh (Eds.), Anorexia nervosa and related eating disorders in childhood and adolescence (pp. 27-40). East Sussex, England: Psychology Press.

"Bryant-Waugh, R. J., Cooper, P. J., Taylor, C. L., \& Lask, B. D. (1996). The use of the Eating Disorder Examination with children: A pilot study. International Journal of Eating Disorders, 19, 391-397.

Bulik, C. M., Sullivan, P. F., \& Kendler, K. S. (2000). An empirical study of the classification of eating disorders. American Journal of Psychiatry, 157, 886-895.

*Bunnell, D. W., Cooper, P. J., Hertz, S., \& Shenker, I. R. (1992). Body shape concerns among adolescents. International Journal of Eating Disorders, 11, 79-83.

*Button, E. J., Benson, E., Nollett, C., \& Palmer, R. (2005). Don't forget EDNOS (eating disorder not otherwise specified): Patterns of service use in an eating disorders service. Psychiatric Bulletin, 29, 134-136.

"Cachelin, F. M., \& Maher, B. A. (1998). Is amenorrhea a critical criterion for anorexia nervosa? Journal of Psychosomatic Research, 44, 435-440.

"Cachelin, F. M., Striegel-Moore, R. H., Elder, K. A., Pike, K. M., Wilfley, D. E., \& Fairburn, C. G. (1999). Natural course of a community sample of women with binge eating disorder. International Journal of Eating Disorders, 25, 45-54.

"Carlat, D. J., Camargo, C. A., Jr., \& Herzog, D. B. (1997). Eating disorders in males: A report on 135 patients. American Journal of Psychiatry, 154, 1127-1132.

*Cartiglia, M. C. (1995). Binge eating disorder and comorbid psychopathology in a college student sample. Dissertation Abstracts International 57(07), 4697B. (UMI No. 9640171)
*Casasnovas, C., Fernandez-Aranda, F., Granero, R., Krug, I., JimenezMurcia, S., Bulik, C. M., et al. (2007). Motivation to change in eating disorders: Clinical and therapeutic implications. European Eating Disorders Review, 15, 449-456.

Chamay-Weber, C., Narring, F., \& Michaud, P.-A. (2005). Partial eating disorders among adolescents: A review. Journal of Adolescent Health, $37,417-427$

*Clinton, D. N., \& Glant, R. (1992). The eating disorders spectrum of $D S M-I I I-R$ : Clinical features and psychosocial concomitants of 86 consecutive cases from a Swedish urban catchment area. Journal of Nervous \& Mental Disease, 180, 244-250.

*Clinton, D., \& Norring, C. (1999). The Rating of Anorexia and Bulimia (RAB) Interview: Development and preliminary validation. European Eating Disorders Review, 7, 362-371.

*Clinton, D., \& Norring, C. (2005). The comparative utility of statistically derived eating disorder clusters and $D S M-I V$ diagnoses: Relationship to symptomatology and psychiatric comorbidity at intake and follow-up. Eating Behaviors, 6, 403-418.

Cohen, J. (1988). Statistical power analysis for the behavioral sciences (2nd ed.). Hillsdale, NJ: Erlbaum.

*Corbridge, C., \& Bell, L. (1996). An audit of people with eating disorders treated by adult mental health services. European Eating Disorders Review, 4, 241-248.

*Crow, S. J., Agras, W. S., Halmi, K., Mitchell, J. E., \& Kraemer, H. C. (2002). Full syndromal versus subthreshold anorexia nervosa, bulimia nervosa, and binge eating disorder: A multi-center study. International Journal of Eating Disorders, 32, 309-318.

${ }^{*}$ Cumella, E. J., Wall, A. D., \& Kerr-Almeida, N. (1999). MMPI-A in the inpatient assessment of adolescents with eating disorders. Journal of Personality Assessment, 73, 31-44.

*Cumella, E. J., Wall, A. D., \& Kerr-Almeida, N. (2000). MMPI-2 in the inpatient assessment of women with eating disorders. Journal of Personality Assessment, 75, 387-403.

Dancyger, I. F., \& Garfinkel, P. E. (1995). The relationship of partial syndrome eating disorders to anorexia nervosa and bulimia nervosa. Psychological Medicine, 25, 1019-1025.

Derogatis, L. R., Rickels, K., \& Rock, A. F. (1976). The SCL-90 and the MMPI: A step in the validation of a new self-report scale. British Journal of Psychiatry, 128, 280-289.

"De Zwaan, M., Mitchell, J. E., Seim, H. C., Specker, S. M., Pyle, R. L., Raymond, N. C., et al. (1994). Eating related and general psychopathology in obese females with binge eating disorder. International Journal of Eating Disorders, 15, 43-52.

De Zwaan, M., Mitchell, J. E., Specker, S. M., Pyle, R. L., Mussell, M. P., \& Seim, H. C. (1993). Diagnosing binge eating disorder: Level of agreement between self-report and expert rating. International Journal of Eating Disorders, 14, 289-295.

"Diaz, J. M., Paredes, K. F., Alvarez-Rayon, G., \& Arevalo, R. V. (2003). Evaluation of the psychometric properties of the Mexican Version of the Eating Disorders Inventory (EDI). Thomson Psicologia, 1, 167-176.

*Durham, D. R. (1990). Personality variables among persons with eating disorders. Dissertation Abstracts International, 51(06), 3113B. (UMI No. 9033253)

*Edwin, D. H., \& Andersen, A. E. (1990). Psychometric testing in 76 males with eating disorders. In A. E. Andersen (Ed.), Males with eating disorders (pp. 116-130). New York: Brunner/Mazel.

Eisler, I., Dare, C., Russell, G. F. M., Szmukler, G., Le Grange, D., \& Dodge, E. (1997). Family and individual therapy in anorexia nervosa: A 5-year follow-up. Archives of General Psychiatry, 54, 1025-1030.

*Ekeroth, K., Broberg, A. G., \& Nevonen, L. (2004). Eating disorders and general psychopathology: A comparison between young adult patients and normal controls with and without self-reported eating problems. European Eating Disorders Review, 12, 208-216.

*Ekeroth, K., Engstrom, I., Hagglof, B., \& Broberg, A. G. (2003). Self- 
reported competencies and problems among Swedish girls with eating disorders and a control sample, using the Youth Self-Report. Eating \& Weight Disorders, 8, 274-281.

*Eldredge, K. L., \& Agras, W. S. (1996). Weight and shape overconcern and emotional eating in binge eating disorder. International Journal of Eating Disorders, 19, 73-82.

Engel, S. G., Wittrock, D. A., Crosby, R. D., Wonderlich, S. A., Mitchell, J. E., \& Kolotkin, R. L. (2006). Development and psychometric validation of an eating disorder-specific health-related quality of life instrument. International Journal of Eating Disorders, 39, 62-71.

Fairburn, C. G. (2008). Cognitive behavior therapy and eating disorders. New York: Guilford Press.

Fairburn, C. G., \& Beglin, S. (2008). Eating Disorder Examination Questionnaire (EDE-Q 6.0). In C. G. Fairburn (Ed.), Cognitive behavior therapy and eating disorders (pp. 309-313). New York: Guilford Press.

Fairburn, C. G., \& Bohn, K. (2005). Eating disorder NOS (EDNOS): An example of the troublesome "not otherwise specified" (NOS) category in DSM-IV. Behaviour Research and Therapy, 43, 691-701.

*Fairburn, C. G., Cooper, Z., Bohn, K., O'Connor, M. E., Doll, H. A., \& Palmer, R. L. (2007). The severity and status of eating disorder NOS: Implications for DSM-V. Behaviour Research and Therapy, 45, 17051715.

*Fairburn, C. G., Cooper, Z., Doll, H. A., \& Davies, B. A. (2005). Identifying dieters who will develop an eating disorder: A prospective, population-based study. American Journal of Psychiatry, 162, 22492255.

Fairburn, C. G., Cooper, Z., Doll, H. A., Norman, P., \& O'Connor, M. (2000). The natural course of bulimia nervosa and binge eating disorder in young women. Archives of General Psychiatry, 57, 659-665.

Fairburn, C. G., Cooper, Z., \& O'Connor, M. E. (2008). Eating disorder examination (Edition 16.0D). In C. G. Fairburn (Ed.), Cognitive behavior therapy and eating disorders (pp. 265-308). New York: Guilford Press.

Fairburn, C. G., Jones, R., Peveler, R. C., Carr, S. J., Solomon, R. A., O'Connor, M. E., et al. (1991). Three psychological treatments for bulimia nervosa: A comparative trial. Archives of General Psychiatry, 48, 463-469.

*Favaro, A., \& Santonastaso, P. (1996). Purging behaviors, suicide attempts, and psychiatric symptoms in 398 eating disordered subjects. International Journal of Eating Disorders, 20, 99-103.

"Favaro, A., \& Santonastaso, P. (1997). Suicidality in eating disorders: Clinical and psychological correlates. Acta Psychiatrica Scandinavica, 95, 508-514.

Feighner, J. P., Robins, E., Guze, S. B., Woodruff, R. A., Winokur, G., \& Muñoz, R. (1972). Diagnostic criteria for use in psychiatric research. Archives of General Psychiatry, 26, 57-63.

Fichter, M. M., Herpertz, S., Quadflieg, N., \& Herpertz-Dahlmann, B. (1998). Structured Interview for Anorexic and Bulimic Disorders for DSM-IV and ICD-10: Updated (third) revision. International Journal of Eating Disorders, 24, 227-249.

Field, A. P. (2003). The problems in using fixed-effects models of metaanalysis on real-world data. Understanding Statistics, 2, 77-96.

First, M. B., Spitzer, R. L., Gibbon, M., \& Williams, J. B. W. (1997). Structured Clinical Interview for DSM-IV Axis I Disorders (SCID-I), Clinician Version. Washington, DC: American Psychiatric Publishing.

"Fitzgibbon, M. L., Sanchez-Johnsen, L. A. P., \& Martinovich, Z. (2003). A test of the continuity perspective across bulimic and binge eating pathology. International Journal of Disorders, 34, 83-97.

*Fontenelle, L. F., Mendlowicz, M. V., Moreira, R. O., \& Appolinario, J. C. (2005). An empirical comparison of atypical bulimia nervosa and binge eating disorder. Brazilian Journal of Medical and Biological Research, 38, 1663-1667.

*Fornari, V. M., Braun, D. L., Sunday, S. R., Sandberg, D. E., Matthews,
M., Chen, I. L., et al. (1994). Seasonal patterns in eating disorder subgroups. Comprehensive Psychiatry, 35, 450-456.

*Friederich, H.-C., Schild, S., Wild, B., de Zwaan, M., Quenter, A., Herzog, W., et al. (2007). Treatment outcome in people with subthreshold compared to full-syndrome binge eating disorder. Obesity, 15, 283287.

*Fullerton, D. T., Wonderlich, S. A., \& Gosnell, B. A. (1995). Clinical characteristics of eating disorder patients who report sexual or physical abuse. International Journal of Eating Disorders, 17, 243-249.

Furukawa, T. A., Barbui, C., Cipriani, A., Brambilla, P., \& Watanabe, N. (2006). Imputing standard deviations in meta-analysis can provide accurate results. Journal of Clinical Epidemiology, 59, 7-10.

Garb, H. N. (1998). Judging the clinician: Judgment research and psychological assessment. Washington, DC: American Psychological Association.

*Garfinkel, P. E., Lin, E., Goering, P., Spegg, C., Goldbloom, D. S., Kennedy, S., et al. (1995). Bulimia nervosa in a Canadian community sample: Prevalence and comparison of subgroups. American Journal of Psychiatry, 152, 1052-1058.

Garner, D. M., Olmstead, M. P., \& Polivy, J. (1983). Development and validation of a multidimensional eating disorder inventory for anorexia nervosa and bulimia. International Journal of Eating Disorders, 2, $15-34$.

*Gerlinghoff, M., Backmund, H., \& Franzen, U. (1998). Evaluation of a day treatment programme for eating disorders. European Eating Disorders Review, 6, 96-106.

${ }^{*}$ Ghadirian, A. M., Marini, N., Jabalpurwala, S., \& Steiger, H. (1999). Seasonal mood patterns in eating disorders. General Hospital Psychiatry, 21, 354-359.

*Gladis, M. M., Wadden, T. A., Foster, G. D., Vogt, R. A., \& Wingate, B. J. (1998). A comparison of two approaches to the assessment of binge eating in obesity. International Journal of Eating Disorders, 23, 17-26.

*Gladis, M. M., Wadden, T. A., Vogt, R., Foster, G., Kuehnel, R. H., \& Bartlett, S. J. (1998). Behavioral treatment of obese binge eaters: Do they need different care? Journal of Psychosomatic Research, 44, 375384.

*Gleaves, D. H., \& Eberenz, K. P. (1995). Correlates of dissociative symptoms among women with eating disorders. Journal of Psychiatric Research, 29, 417-426.

*Gleaves, D. H., Eberenz, K. P., \& May, M. C. (1998). Scope and significance of posttraumatic symptomatology among women hospitalized for an eating disorder. International Journal of Eating Disorders, 24, 147-156.

Gleaves, D. H., Lowe, M. R., Snow, A. C., Green, B. A., \& MurphyEberenz, B. A. (2000). Continuity and discontinuity models of bulimia nervosa: A taxometric investigation. Journal of Abnormal Psychology, 109, 56-68

*Glorio, R., Allevato, M., De Pablo, A., Abbruzzese, M., Carmona, L., Savarin, M., et al. (2000). Prevalence of cutaneous manifestations in 200 patients with eating disorders. International Journal of Dermatology, 39, $348-353$.

*Godt, K. (2002). Personality disorders and eating disorders: The prevalence of personality disorders in 176 female outpatients with eating disorders. European Eating Disorders Review, 10, 102-109.

*Godt, K. (2008). Personality disorders in 545 patients with eating disorders. European Eating Disorders Review, 16, 94-99.

*Goebel, G., Schweiger, U., Kruger, R., \& Fichter, M. M. (1999). Predictors of bone mineral density in patients with eating disorders. International Journal of Eating Disorders, 25, 143-150.

*Griffiths, R. A., Beumont, P. J. V., Russell, J., Schotte, D., Thornton, C., Touyz, S., et al. (1999). Sociocultural attitudes toward appearance in dieting disordered and nondieting disordered subjects. European Eating Disorders Review, 7, 193-203.

Grilo, C. M., Masheb, R. M., \& Wilson, G. T. (2006). Rapid response to 
treatment for binge eating disorder. Journal of Consulting and Clinical Psychology, 74, 602-613.

*Grilo, C. M., Pagano, M. E., Skodol, A. E., Sanislow, C. A., McGlashan, T. H., Gunderson, J. G., et al. (2007). Natural course of bulimia nervosa and of eating disorder not otherwise specified: 5 -year prospective study of remissions, relapses, and the effects of personality disorder psychopathology. Journal of Clinical Psychiatry, 68, 738-746.

*Grisset, N. I., \& Fitzgibbon, M. L. (1996). The clinical significance of binge eating in an obese population: Support for BED and questions regarding its criteria. Addictive Behaviors, 21, 57-66.

Gull, W. W. (1874). Anorexia nervosa (apepsia hysterica, anorexia hysterica). Transactions of the Clinical Society of London, 7, 22-28.

*Hasler, G., Delsignore, A., Milos, G., Buddeberg, C., \& Schnyder, U. (2004). Application of Prochaska's transtheoretical model of change to patients with eating disorders. Journal of Psychosomatic Research, 57, $67-72$.

Hay, P. J., Bacaltchuk, J., \& Stefano, S. (2004). Psychotherapy for bulimia nervosa and binging (review). Cochrane Database of Systematic Reviews, Issue 3, Art. No.: CD000562. DOI: 10.1002/14651858 .CD000562.pub2

Hedley, A. A., Ogden, C. L., Johnson, C. L., Carroll, M. D., Curtin, L. R., \& Flegal, K. M. (2004). Prevalence of overweight and obesity among U.S. children, adolescents, and adults, 1999-2002. Journal of the American Medical Association, 291, 2847-2850.

Herzog, D. B., Hopkins, J. D., \& Burns, C. D. (1993). A follow-up study of 33 subdiagnostic eating disordered women. International Journal of Eating Disorders, 14, 261-267.

Higgs, J. F., Goodyer, I. M., \& Birch, J. (1989). Anorexia nervosa and food avoidance emotional disorder. Archives of Disease in Childhood, 64, 346-351.

Hudson, J. I., Hiripi, E., Pope, H. G., \& Kessler, R. C. (2007). The prevalence and correlates of eating disorders in the National Comorbidity Survey Replication. Biological Psychiatry, 61, 348-358.

Javaras, K. N., Laird, N. M., Reichborn-Kjennerud, T., Bulik, C. M., Pope, H. G., \& Hudson, J. I. (2008). Familiality and heritability of binge eating disorder: Results of a case-control family study and a twin study. International Journal of Eating Disorders, 41, 174-179.

Johnson, J. G., First, M. B., Cohen, P., Skodol, A. E., Kasen, S., \& Brook, J. S. (2005). Adverse outcomes associated with personality disorder not otherwise specified in a community sample. American Journal of Psychiatry, 162, 1926-1932.

*Joyce, J. M., Warren, D. L., Humphries, L. L., Smith, A. J., \& Coon, J. S. (1990). Osteoporosis in women with eating disorders: Comparison of physical parameters, exercise, and menstrual status with SPA and DPA evaluation. Journal of Nuclear Medicine, 31, 325-331.

Keel, P. K., Dorer, D. J., Eddy, K. T., Delinsky, S. S., Franko, D. L., Blais, M. B., et al. (2002). Predictors of treatment utilization among women with anorexia and bulimia nervosa. American Journal of Psychiatry, 159, $140-142$

*Keel, P. K., Haedt, A., \& Edler, C. (2005). Purging disorder: An ominous variant of bulimia nervosa? International Journal of Eating Disorders, 38, 191-199.

Keel, P. K., \& Klump, K. L. (2003). Are eating disorders culture-bound syndromes? Implications for conceptualizing their etiology. Psychological Bulletin, 129, 747-769.

*Keel, P. K., Mayer, S. A., \& Harnden-Fischer, J. H. (2001). Importance of size in defining binge eating episodes in bulimia nervosa. International Journal of Eating Disorders, 29, 294-301.

Keel, P. K., Mitchell, J. E., Miller, K. B., Davis, T. L., \& Crow, S. J. (1999). Long-term outcome of bulimia nervosa. Archives of General Psychiatry, 56, 63-69.

*Keel, P. K., Wolfe, B. E., Liddle, R. A., De Young, K. P., \& Jimerson, D. C. (2007). Clinical features and physiological response to a test meal in purging disorder and bulimia nervosa. Archives of General Psychiatry, 64, 1058-1066.

*Kovacs, D., Mahon, J., \& Palmer, R. L. (2002). Chewing and spitting out food among eating-disordered patients. International Journal of Eating Disorders, 32, 112-115.

*Krug, I., Casasnovas, C., Granero, R., Martinez, C., Jimenez-Murcia, S., Bulik, C. M., et al. (2008). Comparison study of full and subthreshold bulimia nervosa: Personality, clinical characteristics, and short-term response to therapy. Psychotherapy Research, 18, 37-47.

*Kruger, S., Shugar, G., \& Cooke, R. G. (1996). Comorbidity of binge eating disorder and the partial binge eating syndrome with bipolar disorder. International Journal of Eating Disorders, 19, 45-52.

*Kuehnel, R. H., \& Wadden, T. A. (1994). Binge eating disorder, weight cycling, and psychopathology. International Journal of Eating Disorders, 15, 321-329.

*Kurth, C. L., Krahn, D. D., Nairn, K., \& Drewnowski, A. (1995). The severity of dieting and bingeing behaviors in college women: Interview validation of survey data. Journal of Psychiatric Research, 29, 211-225.

Kutlesic, V., Williamson, D. A., Gleaves, D. H., Barbin, J. M., \& MurphyEberenz, K. P. (1998). The Interview for the Diagnosis of Eating Disorders-IV: Application to DSM-IV diagnostic criteria. Psychological Assessment, 10, 41-48.

Kuwabara, H., Otsuka, M., Shindo, M., Ono, S., Shiori, T., \& Someya, T. (2007). Diagnostic classification and demographic features in 283 patients with somatoform disorder. Psychiatry and Clinical Neurosciences, $61,283-289$

Landis, J. R., \& Koch, G. G. (1977). The measurement of observer agreement for categorical data. Biometrics, 33, 159-174

Laségue, C. (1873). On hysterical anorexia. Medical Times and Gazette, 2, 265-266.

"Lee, S., Chan, Y. Y. L., \& Hsu, L. K. G. (2003). The intermediate-term outcome of Chinese patients with anorexia nervosa in Hong Kong. American Journal of Psychiatry, 160, 967-972.

"Lee, S., Ho, T. P., \& Hsu, L. K. G. (1993). Fat phobic and non-fat phobic anorexia nervosa: A comparative study of 70 Chinese patients in Hong Kong. Psychological Medicine, 23, 999-1017.

${ }^{*}$ Lee, S., Kwok, K., Liau, C., \& Leung, T. (2002). Screening Chinese patients with eating disorders using the Eating Attitudes Test in Hong Kong. International Journal of Eating Disorders, 32, 91-97.

*Lee, S., Lee, A. M., \& Leung, T. (1998). Cross-cultural validity of the Eating Disorder Inventory: A study of Chinese patients with eating disorders in Hong Kong. International Journal of Eating Disorders, 23 $177-188$.

"Lee, S., Lee, A. M., Ngai, E., Lee, D. T. S., \& Wing, Y. K. (2001). Rationales for food refusal in Chinese patients with anorexia nervosa. International Journal of Eating Disorders, 29, 224-229.

*Le Grange, D., Binford, R. B., Peterson, C. B., Crow, S. J., Crosby, R. D. Klein, M. H., et al. (2006). DSM-IV threshold versus subthreshold bulimia nervosa. International Journal of Eating Disorders, 39, 462467.

Le Grange, D., \& Lock, J. (2005). The dearth of psychological treatment studies for anorexia nervosa. International Journal of Eating Disorders, 37, 79-91.

*Le Grange, D., Loeb, K. L., Van Orman, S., \& Jellar, C. C. (2004). Bulimia nervosa in adolescents: A disorder in evolution? Archives of Pediatric Adolescent Medicine, 158, 478-482.

*Levine, J., Gur, E., Loewenthal, R., Vishne, T., Dwolatzky, T., van Beynum, I., et al. (2007). Plasma homocysteine levels in female patients with eating disorders. International Journal of Eating Disorders, 40, 277-284.

Lipsey, M. W., \& Wilson, D. B. (2001). Practical meta-analysis. Thousand Oaks, CA: Sage.

Machado, P. P. P., Machado, B. C., Goncalves, S., \& Hoek, H. W. (2007) 
The prevalence of eating disorders not otherwise specified. International Journal of Eating Disorders, 40, 212-217.

Mangweth-Matzek, B., Rupp, C. I., Hausmann, A., Assmayr, K., Mariacher, E., Kemmler, G., et al. (2006). Never too old for eating disorders or body dissatisfaction: A community study of elderly women. International Journal of Eating Disorders, 39, 583-586.

*Marañon, I., Echeburua, E., \& Grijalvo, J. (2004). Prevalence of personality disorders in patients with eating disorders: A pilot study using the IPDE. European Eating Disorders Review, 12, 217-222.

*Martin, C. K., Williamson, D. A., \& Thaw, J. M. (2000). Criterion validity of the multiaxial assessment of eating disorders symptoms. International Journal of Eating Disorders, 28, 303-310.

*McDermott, B., Forbes, D., Harris, C., McCormack, J., \& Gibbon, P. (2006). Non-eating disorders psychopathology in children and adolescents with eating disorders: Implications for malnutrition and symptom severity. Journal of Psychosomatic Research, 60, 257-261.

McIntosh, V. V. W., Jordan, J., Carter, F. A., Luty, S. E., McKenzie, J. M., Bulik, C. M., et al. (2005). Three psychotherapies for anorexia nervosa: A randomized, controlled trial. American Journal of Psychiatry, 162, 741-747.

*Miller, P. M., Watkins, J. A., Sargent, R. G., \& Rickert, E. J. (1999). Self-efficacy in overweight individuals with binge eating disorder. Obesity Research, 7, 552-555.

Miller, P. R., Dasher, R., Collins, R., Griffiths, P., \& Brown, F. (2001). Inpatient diagnostic assessments: I. Accuracy of structured vs. unstructured interviews. Psychiatry Research, 105, 255-264.

*Milos, G. F., Spindler, A. M., Buddeberg, C., \& Crameri, A. (2003). Axes I and II comorbidity and treatment experiences in eating disorder subjects. Psychotherapy \& Psychosomatics, 72, 276-285.

*Milos, G., Spindler, A., Hepp, U., \& Schnyder, U. (2004). Suicide attempts and suicidal ideation: Links with psychiatric comorbidity in eating disorder subjects. General Hospital Psychiatry, 26, 129-135.

Milos, G., Spindler, A., Schnyder, U., \& Fairburn, C. G. (2005). Instability of eating disorder diagnoses: Prospective study. British Journal of Psychiatry, 187, 573-578.

Mitchell, J. E., Cook-Myers, T., \& Wonderlich, S. A. (2005). Diagnostic criteria for anorexia nervosa: Looking ahead to the DSM-V. International Journal of Eating Disorders, 37, S95-S97.

Mitchell, J. E., Crosby, R. D., Wonderlich, S. A., Hill, L., Le Grange, D., Powers, P., \& Eddy, K. (2007). Latent profile analysis of a cohort of patients with eating disorders not otherwise specified. International Journal of Eating Disorders, 40, S95-S98.

"Mizes, J. S., Christiano, B., Madison, J., Post, G., Seime, R., \& Varnado, P. (2000). Development of the Mizes Anorectic Cognitions Questionnaire-Revised: Psychometric properties and factor structure in a large sample of eating disorder patients. International Journal of Eating Disorders, 28, 415-421.

*Mizes, J. S., Heffner, M., Madison, J. K., \& Varnado-Sullivan, P. (2004). The validity of subjective measures of body image disturbance. Eating Behaviors, 5, 55-66.

*Moor, S., Vartanian, L. R., Touyz, S. W., \& Beumont, P. J. V. (2004). Psychopathology of EDNOS patients: To whom do they compare? Clinical Psychologist, 8, 70-75.

*Moreno, A., \& Thelen, M. H. (1993). Parental factors related to bulimia nervosa. Addictive Behaviors, 18, 681-689.

Napolitano, M. A., Head, S., Babyak, M. A., \& Blumenthal, J. A. (2001). Binge eating disorder and night eating syndrome: Psychological and behavioral characteristics. International Journal of Eating Disorders, 30, 193-203.

National Institute for Clinical Excellence. (2004). Eating disorders: Core interventions in the treatment and management of anorexia nervosa, bulimia nervosa, and related eating disorders. London: British Psychological Society.
*Nevonen, L., \& Broberg, A. G. (2001). Validating the Eating Disorder Inventory-2 (EDI-2) in Sweden. Eating \& Weight Disorders, 6, 59-67.

Nicholls, D., Chater, R., \& Lask, B. (2000). Children into DSM don't go: A comparison of classification systems of eating disorders for children. International Journal of Eating Disorders, 28, 317-324.

*Nollett, C. L., \& Button, E. J. (2005). Questionnaire measures of psychopathology in eating disorders: Comparisons between clinical groups. European Eating Disorders Review, 13, 211-215.

*Noma, S., Nakai, Y., Hamagaki, S., Uehara, M., Hayashi, A., \& Hayashi, T. (2006). Comparison between the SCOFF questionnaire and the Eating Attitudes Test in patients with eating disorders. International Journal of Psychiatry in Clinical Practice, 10, 27-32.

*Orbitello, B., Ciano, R., Corsaro, M., Rocco, P. L., Taboga, C., Tonutti, L., et al. (2006). The EAT-26 as screening instrument for clinical nutrition unit attenders. International Journal of Obesity, 30, 977-981.

Orwin, R. G. (1983). A fail-safe $N$ for effect size in meta-analysis. Journal of Educational Statistics, 8, 157-159.

*Panagiotopoulos, C., McCrindle, B. W., Hick, K., \& Katzman, D. K. (2000). Electrocardiographic findings in adolescents with eating disorders. Pediatrics, 105, 1100-1105.

Peterson, C. B., Mitchell, J. E., Engbloom, S., Nugent, S., Mussell, M. P., Crow, S. J., et al. (2001). Self-help versus therapist-led group cognitive behavioral treatment of binge eating disorder at follow-up. International Journal of Eating Disorders, 30, 363-374.

Pincus, H. A., Frances, A., Davis, W. W., First, M. B., \& Widiger, T. A. (1992). DSM-IV and new diagnostic categories: Holding the line on proliferation. American Journal of Psychiatry, 149, 112-117.

Pinheiro, A. P., Bulik, C. M., Sullivan, P. F., \& Machado, P. P. P. (2008). An empirical study of the typology of bulimic symptoms in young Portuguese women. International Journal of Eating Disorders, 41, 251258.

Pope, H. G., Lalonde, J. K., Pindyck, L. J., Walsh, T., Bulik, C. M., Crow, S. J., et al. (2006). Binge eating disorder: A stable syndrome. American Journal of Psychiatry, 163, 2181-2183.

*Probst, M., Vandereycken, W., Van Coppenolle, H., \& Vanderlinden, J. (1995). The Body Attitude Test for patients with an eating disorder: Psychometric characteristics of a new questionnaire. Eating Disorders, 3, 133-144.

*Raymond, N. C., de Zwaan, M., Mitchell, J. E., Ackard, D., \& Thuras, P. (2002). Effect of a very low calorie diet on the diagnostic category of individuals with binge eating disorder. International Journal of Eating Disorders, 31, 49-56.

*Resch, M., Szendei, G., \& Haasz, P. (2004). Bulimia from a gynecological view: Hormonal changes. Journal of Obstetrics \& Gynaecology, 24 907-910.

*Ricca, V., Mannucci, E., Mezzani, B., Di Bernardo, M., Zucchi, T., Paionni, A., et al. (2001). Psychopathological and clinical features of outpatients with an eating disorder not otherwise specified. Eating \& Weight Disorders, 6, 157-165.

Ringham, R., Klump, K., Kaye, W., Stone, D., Libman, S., Stowe, S., \& Marcus, M. (2006). Eating disorder symptomatology among ballet dancers. International Journal of Eating Disorders, 39, 503-508.

*Riva, G., Bacchetta, M., Baruffi, M., Cirillo, G., \& Molinari, E. (2000). Virtual reality environment for body image modification: A multidimensional therapy for the treatment of body image in obesity and related pathologies. CyberPsychology \& Behavior, 3, 421-431.

*Ro, O., Martinsen, E. W., Hoffart, A., \& Rosenvinge, J. (2005). Two-year prospective study of personality disorders in adults with longstanding eating disorders. International Journal of Eating Disorders, 37, 112 118.

*Roberto, C. A., Steinglass, J., Mayer, L., Attia, E., \& Walsh, B. T. (2007). The clinical significance of amenorrhea as a diagnostic criterion for anorexia nervosa. Unpublished manuscript, Yale University, New Haven, CT. 
Rockert, W., Kaplan, A. S., \& Olmsted, M. P. (2007). Eating disorder not otherwise specified: The view from a tertiary care treatment center. International Journal of Eating Disorders, 40, S99-S103.

Rosenthal, R. (1979). The "file drawer problem" and tolerance for null results. Psychological Bulletin, 86, 638-641.

Rosenthal, R. (1995). Writing meta-analytic reviews. Psychological Bulletin, 118, 183-192.

Rosenthal, R., Rosnow, R. L., \& Rubin, D. B. (2000). Contrasts and effect sizes in behavioral research: A correlational approach. New York: Cambridge University Press.

Russell, G. (1979). Bulimia nervosa: An ominous variant of anorexia nervosa. Psychological Medicine, 9, 429-448.

*Salvemini, V., Berna, G., Foca, F., Indrimi, M., Sammartino, F., Spinosa, L., et al. (2000). Differences and similarities in the personality structure of 327 women with eating disorders. Eating \& Weight Disorders, 5, $108-115$.

Sar, V., Akyuz, G., \& Dogan, O. (2007). Prevalence of dissociative disorders among women in the general population. Psychiatry Research, 149, 169-176.

*Schaefer, W. K., Maclennan, R. N., Yaholnitsky-Smith, S. A., \& Stover, E. D. (1998). Psychometric evaluation of the Eating Disorder Inventory (EDI) in a clinical group. Psychology and Health, 13, 873-881.

Schmidt, U., Landau, S., Pombo-Carril, M. G., Bara-Carril, N., Reid, Y., Murray, K., et al. (2006). Does personalized feedback improve the outcome of cognitive-behavioral guided self-care in bulimia nervosa? A preliminary randomized controlled trial. British Journal of Clinical Psychology, 45, 111-121.

*Schork, E. J., Eckert, E. D., \& Halmi, K. A. (1994). The relationship between psychopathology, eating disorder diagnosis, and clinical outcome at 10-year follow-up in anorexia nervosa. Comprehensive Psychiatry, 35, 113-123.

"Shafran, R., Fairburn, C. G., Robinson, P., \& Lask, B. (2004). Body checking and its avoidance in eating disorders. International Journal of Eating Disorders, 35, 93-101.

Shapiro, J. R., Berkman, N. D., Browneley, K. A., Sedway, J. A., Lohr, K. N., \& Bulik, C. M. (2007). Bulimia nervosa: A systematic review of randomized controlled trials. International Journal of Eating Disorders, 40, 321-336.

Shear, M. K., Greeno, C., Kang, J., Ludewig, D., Frank, E., Swartz, H. A., \& Hanekamp, M. (2000). Diagnosis of nonpsychotic patients in community clinics. American Journal of Psychiatry, 157, 581-587.

"Sherwood, N. E., Crowther, J. H., Wills, L., \& Ben-Porath, Y. S. (2000). The perceived function of eating for bulimic, subclinical bulimic, and non-eating disordered women. Behavior Therapy, 31, 777-793.

*Siervo, M., Boschi, V., Papa, A., Bellini, O., \& Falconi, C. (2005). Application of the SCOFF, Eating Attitude Test 26 (EAT 26) and Eating Inventory (TFEQ) questionnaires in young women seeking diet-therapy. Eating \& Weight Disorders, 10, 76-82.

*Solenberger, S. E. (2001). Exercise and eating disorders: A 3-year inpatient hospital record analysis. Eating Behaviors, 2, 151-168.

Speilmans, G. I., Pasek, L. F., \& McFall, J. P. (2007). What are the active ingredients in cognitive and behavioral psychotherapy for anxious and depressed children? A meta-analytic review. Clinical Psychology Review, 27, 642-654

Spielberger, C., Gorsuch, R. L., Lushene, R., Vagg, P. R., \& Jacobs, G. A. (1983). The State-Trait Anxiety Inventory. Palo Alto, CA: Consulting Psychologists Press.

*Spindler, A., \& Milos, G. (2007). Links between eating disorder symptom severity and psychiatric comorbidity. Eating Behaviors, 8, 364-373.

Spitzer, R. L., Devlin, M., Walsh, B. T., Hasin, D., Wing, R., Marcus, M., et al. (1991). Binge eating disorder: To be or not to be in DSM-IV? International Journal of Eating Disorders, 10, 627-629.

Spitzer, R. L., Devlin, M., Walsh, B. T., Hasin, D., Wing, R., Marcus, M., et al. (1992). Binge eating disorder: A multi-site field trial of the diagnostic criteria. International Journal of Eating Disorders, 11, 191203.

Spitzer, R. L., Yanovski, S., Wadden, T., Wing, R., Marcus, M. D., Stunkard, A., et al. (1993). Binge eating disorder: Its further validation in a multisite study. International Journal of Eating Disorders, 2, 137-153.

Steinhausen, H.-C. (2002). The outcome of anorexia nervosa in the 20th century. American Journal of Psychiatry, 159, 1284-1293.

Stice, E., Fisher, M., \& Martinez, E. (2004). Eating Disorder Diagnostic Scale: Additional evidence of reliability and validity. Psychological Assessment, 16, 60-71.

*Stice, E., Killen, J. D., Hayward, C., \& Taylor, C. B. (1998). Support for the continuity hypothesis of bulimic pathology. Journal of Consulting and Clinical Psychology, 66, 784-790.

*Striegel-Moore, R. H., Dohm, F. A., Solomon, E. E., Fairburn, C. G., Pike, K. M., \& Wilfley, D. E. (2000). Subthreshold binge eating disorder. International Journal of Eating Disorders, 27, 270-278.

Striegel-Moore, R. H., \& Franko, D. L. (2008). Should binge eating disorder be included in the $D S M-V$ ? A critical review of the state of the evidence. Annual Review of Clinical Psychology, 4, 305-324.

Striegel-Moore, R. H., Franko, D. L., Thompson, D., Barton, B., Schreiber, G. B., \& Daniels, S. R. (2005). An empirical study of the typology of bulimia nervosa and its spectrum variants. Psychological Medicine, 35, $1563-1572$

Striegel-Moore, R. H., Garvin, V., Dohm, F.-A., \& Rosenheck, R. A. (1999). Psychiatric comorbidity of eating disorders in men: A national study of hospitalized veterans. International Journal of Eating Disorders, 25, 399-404.

Strober, M., Freeman, R., \& Morrell, W. (1999). Atypical anorexia nervosa: Separation from typical cases in course and outcome in a longterm prospective study. International Journal of Eating Disorders, 25, 135-142.

Stunkard, A. J. (1959). Eating patterns and obesity. Psychiatric Quarterly, 33, 284-295.

Stunkard, A. J., Grace, W. J., \& Wolff, H. G. (1955). The night-eating syndrome; a pattern of food intake among certain obese patients. American Journal of Medicine, 19, 78-86.

Sullivan, P. F., Bulik, C. M., \& Kendler, K. S. (1998). The epidemiology of bulimia nervosa: Symptoms, syndromes, and diagnostic thresholds. Psychological Medicine, 28, 599-610.

Thaw, J. M., Williamson, D. A., \& Martin, C. K. (2001). Impact of altering $D S M-I V$ criteria for anorexia and bulimia nervosa on the base rates of eating disorder diagnoses. Eating and Weight Disorders, 6, 121-129.

Thomas, J. J., Roberto, C. A., \& Brownell, K. D. (In press). Eighty-five percent of what? Discrepancies in the weight cut-off for anorexia nervosa substantially affect the prevalence of underweight. Psychological Medicine.

*Thurfjell, B., Edlund, B., Arinell, H., Hagglof, B., \& Engstrom, I. (2003). Psychometric properties of Eating Disorder Inventory for children (EDI-C) in Swedish girls with and without a known eating disorder. Eating \& Weight Disorders, 8, 296-303.

*Tobin, D. L., Griffing, A., \& Griffing, S. (1997). An examination of subtype criteria for bulimia nervosa. International Journal of Eating Disorders, 22, 179-186.

*Troop, N. A., Murphy, F., Bramon, E., \& Treasure, J. L. (2000). Disgust sensitivity in eating disorders: A preliminary investigation. International Journal of Eating Disorders, 27, 446-451.

*Turner, H., \& Bryant-Waugh, R. (2004). Eating disorder not otherwise specified (EDNOS): Profiles of clients presenting at a community eating disorder service. European Eating Disorders Review, 12, 18-26.

*Vandereycken, W., \& Pieters, G. (1992). A large-scale longitudinal follow-up study of patients with eating disorders: Methodological issues and preliminary results. In W. Herzog, H.-C. Deter, \& W. Vandereycken (Eds.), The course of eating disorders: Long-term follow-up studies of 
anorexia and bulimia nervosa (pp. 182-197). New York: SpringerVerlag.

*Vanderlinden, J., Vandereycken, W., van Dyck, R., \& Vertommen, H. (1993). Dissociative experiences and trauma in eating disorders. International Journal of Eating Disorders, 13, 187-193.

*Vaz, F. J., Penas, E. M., \& Ramos, M. I. (1999). Body image dissatisfaction in bulimia nervosa and atypical bulimia nervosa. German Journal of Psychiatry, 2, 59-74.

Wade, T. D., Bergin, J. L., Tiggemann, M., Bulik, C. M., \& Fairburn, C. G. (2006). Prevalence and long-term course of lifetime eating disorders in an adult Australian twin cohort. Australian and New Zealand Journal of Psychiatry, 40, 121-128.

Walsh, B. T., Kaplan, A. S., Attia, E., Olmsted, M., Parides, M., Carter, J. C., et al. (2006). Fluoxetine after weight restoration in anorexia nervosa. A randomized controlled trial. Journal of the American Medical Association, 295, 2605-2612.

*Watson, T. L., \& Andersen, A. E. (2003). A critical examination of the amenorrhea and weight criteria for diagnosing anorexia nervosa. Acta Psychiatrica Scandinavica, 108, 175-182.

Weisz, J. R., McCarty, C. A., \& Valeri, S. M. (2006). Effects of psychotherapy for depression in children and adolescents: A meta-analysis. Psychological Bulletin, 132, 132-149.

*Weltzin, T. E., Weisensel, N., Cornella-Carlson, T., \& Bean, P. (2007). Improvements in the severity of eating disorder symptoms and weight changes in a large population of males undergoing treatment for eating disorders. Unpublished manuscript, Rogers Memorial Hospital, Oconomowoc, WI.

Westen, D., \& Arkowitz-Westen, L. (1998). Limitations of Axis II in diagnosing personality pathology in clinical practice. American Journal of Psychiatry, 155, 1767-1771.

Widiger, T. A. (1993). The DSM-III-R categorical personality disorder diagnoses: A critique and an alternative. Psychological Inquiry, 4, 7590 .

*Wildes, J. E. (2003). Challenges to the diagnostic classification of bulimia nervosa: Partial-syndrome presentation and comorbidity with major depression. Dissertation Abstracts International, 64(08), 4070B. (UMI No. 3102194)

Wilfley, D. E., Welch, R. R., Stein, R. I., Spurrell, E. B., Cohen, L. R., Saelens, B. E., et al. (2002). A randomized comparison of group cognitive-behavioral therapy and group interpersonal psychotherapy for the treatment of overweight individuals with binge-eating disorder. Archives of General Psychiatry, 59, 713-721.

*Wilks, D., Jr. (2006). The role of emotional dysregulation in the treatment of eating disorders. Dissertation Abstracts International, 66(12). (UMI No. 3198495)

*Williamson, D. A., Gleaves, D. H., \& Savin, S. S. (1992). Empirical classification of eating disorder not otherwise specified: Support for DSM-IV changes. Journal of Psychopathology and Behavioral Assessment, 14, 201-216.

Williamson, D. A., Gleaves, D. H., \& Stewart, T. M. (2005). Categorical versus dimensional models of eating disorders: An examination of the evidence. International Journal of Eating Disorders, 37, 1-10.

*Williamson, D. A., Womble. L. G., Smeets, M. A. M., Netemeyer, R. G., Thaw, J. M., Kutlesic, V., et al. (2002). Latent structure of eating disorder symptoms: A factor analytic and taxometric investigation. American Journal of Psychiatry, 159, 412-418.

Wolk, S. L., Loeb, K. L., \& Walsh, B. T. (2005). Assessment of patients with anorexia nervosa: Interview versus self-report. International Journal of Eating Disorders, 37, 92-99.

Wonderlich, S. A., Crosby, R. D., Mitchell, J. E., \& Engel, S. G. (2007). Testing the validity of eating disorder diagnoses. International Journal of Eating Disorders, 40, S40-S45.

World Health Organization. (1977). International statistical classification of diseases and related health problems (9th ed.). Geneva, Switzerland: Author.

World Health Organization. (1992-1994). International Statistical Classification of Diseases and Related Health Problems (10th ed.). Geneva, Switzerland: Author.

*Wunderlich, U., Gerlinghoff, M., \& Backmund, H. (2004). Eating disturbances in siblings of patients with eating disorders. Eating \& Weight Disorders, 9, 258-263.

Zimmerman, M., Francione-Witt, C., Chelminski, I., Young, D., \& Tortolani, C. (2008). Problems applying the DSM-IV eating disorders diagnostic criteria in a general psychiatric outpatient practice. Journal of Clinical Psychiatry, 69, 381-384.

Received February 25, 2008 Revision received December 18, 2008 Accepted December 27, 2008 